1

2

3

4

\title{
Brain orchestration of pregnancy and maternal behavior in mice
}

David André Barrière ${ }^{1,2 \#}$, Arsène Ella ${ }^{1,3}$, Frédéric Szeremeta ${ }^{4}$, Hans Adriaensen ${ }^{1}$, William

Même $^{4}$, Elodie Chaillou ${ }^{1}$, Martine Migaud $^{1}$, Sandra Même $^{4}$, Frédéric Lévy ${ }^{1}$,

Matthieu Keller ${ }^{1, \#}$

\section{7}

${ }^{1}$ Physiologie de la Reproduction et des Comportements, UMR INRAE/CNRS/Université de Tours/IFCE, Nouzilly, France.

${ }^{2}$ Université Paris-Saclay, CEA, CNRS, BAOBAB, NeuroSpin, 91191, Gif-Sur-Yvette, France. ${ }^{3}$ MRC Cognition and Brain Sciences Unit, University of Cambridge, UK.

${ }^{4}$ Complexes Métalliques et IRM, Centre de Biophysique Moléculaire, UPR44301 CNRS, Orléans, France.

\section{${ }^{\#}$ Corresponding authors:}

matthieu.keller@inrae.fr and david.a.barriere@gmail.com 


\section{$17 \underline{\text { Abstract }}$}

18 Reproduction induces changes within the brain to prepare for gestation and motherhood.

19 However, the dynamic of these central changes and their relationships with the development

20 of maternal behavior remain poorly understood. Here, we describe a longitudinal

21 morphometric neuroimaging study in female mice between pre-gestation and weaning, using

22 new magnetic resonance imaging (MRI) resources comprising a high-resolution brain

23 template, its associated tissue priors $(60-\mu \mathrm{m}$ isotropic resolution) and a corresponding mouse

24 brain atlas (1320 regions of interest). Using these tools, we observed transient hypertrophies

25 not only within key regions controlling gestation and maternal behavior (medial preoptic area,

26 bed nucleus of the stria terminalis), but also in the amygdala, caudate nucleus and

27 hippocampus. Additionally, unlike females exhibiting lower levels of maternal care, highly

28 maternal females developed transient hypertrophies in somatosensory, entorhinal and

29 retrosplenial cortices among other regions. Therefore, coordinated and transient brain

30 modifications associated with maternal performance occurred during gestation and lactation.

32 Key words: Gestation, lactation, maternal brain, MRI, atlas, voxel-based morphometry. 


\section{Abbreviations:}

34 AC-PC: anterior commissure-posterior commissure

35 AMBMC: Australian Mouse Brain Mapping Consortium

36 AOB: accessory olfactory bulb

37 BNST: bed nucleus of the stria terminalis

38 CNS: central nervous system

39 CSF: cerebrospinal fluid

40 DARTEL: diffeomorphic anatomical registration using exponentiated lie algebra

41 df: degree of freedom

$42 \quad$ FA: flip angle

43 FLASE: fast large-angle spin-echo

$44 \quad$ FoV: field of view

45 MRI: magnetic resonance imaging

46 MOB: main olfactory bulb

47 mPOA: medial preoptic area

48 GM: gray matter

49 GMC: gray matter concentration

50 PVN: paraventricular nucleus of the hypothalamus

51 RARE: rapid acquisition with relaxation enhancement

52 ROC: receiver operating characteristic

53 ROI: region of interest

54 TE: echo time

55 TR: repetition time

56 VBM: voxel-based morphometry

57 WM: white matter 


\section{Introduction}

Motherhood is among the most transformative experiences in the lives of female mammals. While virgin females tend to avoid neonates, the end of the gestation period and the birth process lead to a behavioral switch characterized by an attraction towards infant cues, the expression of nurturing behavior and ultimately the establishment of infant bonding $^{1,2}$. Decades of scientific research dedicated to the maternal brain have revealed a core neural circuitry that includes the medial preoptic area (mPOA) and the adjoining ventral part of the bed nucleus of the stria terminalis (BNSTv), and that is highly critical for the onset of maternal behavior ${ }^{1,3-5}$. Functional modulations of the mPOA/BNSTv consistently disrupt maternal motivation and expression in numerous species ${ }^{1,2,6}$. This core maternal circuitry regulates maternal behavior through its direct projections to the ventral tegmental area, which promotes reward system activation ${ }^{1,7}$, as well as through its connections with cortical regions, including the prefrontal cortex ${ }^{8-10}$. This crucial central circuitry is finely regulated by multiple neural networks that integrate both internal and external stimulations. The proper expression of maternal care towards offspring is prepared through the neuroendocrine action of sex steroids and neuropeptides such as oxytocin among others during the gestation period ${ }^{11}$. These internal factors induce rewiring of the maternal brain, including through structural plasticity through increasing neuronal soma size or astrocytic complexity within the $\mathrm{mPOA}^{12}$, and changes in neurogenesis mainly in the main olfactory bulb (MOB) ${ }^{13}$ but also in the mPOA/BNST in rodents ${ }^{14}$. In human, regional morphological changes of gray matter (GM) within the parahippocampal gyrus, precuneus, cingulate, insula and frontal cortex have been observed in primiparous women using magnetic resonance imaging (MRI) ${ }^{15}$. Additionally, olfactory cues coming from the neonate are integrated by the MOB and the accessory olfactory bulb (AOB) through an amygdalo-hypothalamic pathway, which is responsible for attraction/repulsion behavioral outcomes ${ }^{16}$. Hence, the development of the maternal brain is 
dependent on both integration of external and internal cues acting through multiple brain pathways and regions to prepare the brain to gestation and motherhood. Nevertheless, the relationship between the brain rewiring over the gestation and lactation periods and the establishment of the maternal behavior is poorly documented.

To assess the dynamics of the maternal brain, a longitudinal MRI morphometric study over a complete reproductive experience was performed in mouse to investigate changes in the gray matter concentration (GMC) using voxel-based morphometry (VBM). VBM is a well-established and well-validated image analysis technique that provides an unbiased and comprehensive assessment of anatomical differences throughout the brain, and has been successfully used to study GM changes within the mouse brain ${ }^{17-21}$. However, available mouse brain MRI resources are often partial or provided in different spatial orientations or spatial resolutions (Table 1). As an example, the Australian Mouse Brain Mapping Consortium (AMBMC), offers a high resolutive template and detailed atlases of the mouse brain including the cerebellum ${ }^{22}$, hippocampus ${ }^{23}$, diencephalon ${ }^{24}$ and cortices ${ }^{25}$. Unfortunately, segmentation of the $\mathrm{MOB}$ and the $\mathrm{AOB}$ and hindbrain is lacking, and this resource does not provide associated tissues probabilistic maps necessary for VBM. In other hand, the Allen Mouse Brain Common Coordinate Framework, is the most advanced mouse brain atlas ${ }^{26}$. This new atlas delimitates discrete structures within the thalamus, hindbrain, olfactory system and diencephalon and provides a full segmentation of cortical layers however, MRI template and brain tissues priors are still lacking for VBM investigations.

Thus, we combined these resources and associated probabilistic maps to emulate a complete resource dedicated to the mouse brain. Using these resources and a longitudinal VBM approach, we were able to assess the dynamic morphological changes of the brain during the whole reproductive period and demonstrate how these changes predict the quality of maternal behavior. 
$\underline{\text { Results }}$

109

110

111

112

\section{Mouse MRI atlas}

VBM strategies require a template image and its associated priors of gray matter (GM), white matter (WM) and cerebrospinal fluid (CSF) for brain segmentation and normalization. In addition, a complete atlas of the mouse brain is mandatory for the identification of regions of interest (ROIs) highlighted by the VBM analysis. Given the limitations of available tools to thoroughly study GMC changes during the gestation and lactation periods in mice, we developed first a new set of resources using the AMBMC, an ultra-high-resolution template built from ex vivo brain images finely normalized within the same space $^{25}$ and the Allen Mouse Brain Common Coordinate Framework ${ }^{26}$ (Figure 1). Our resources comprise the following four components: 1) a complete mouse brain template with a spatial resolution suitable for mouse brain analysis (60- $\mu$ m isotropic resolution); 2) the corresponding GM, WM and CSF probabilistic maps for brain normalization together with a VBM analysis built from $138 \mathrm{~T}_{2}$-weighted images; 3) a complete mouse brain atlas derived from Paxinos and Franklin's mouse brain atlas ${ }^{27}$ and composed of a mosaic of 1320 ROIs (Figure 2A); 4) a brain mesh permitting brain plot generation and data visualization (Figure 2B and Supplemental Video 1). We visually inspected and carefully checked the results of the normalization process against the original coregistered atlas. Then, the labeled structures were reclassified and aggregated according to the brain regions to which they belonged (auditory, insular, temporal cortices, etc.), with respect to their anatomical topography (cortex, basal ganglia, etc.), tissue type (GM, WM and CSF) and hemisphere (left or right). Cortical structures were subdivided into functional (e.g., primary and secondary motor cortices) or structural (agranular, dysgranular, agranular/dysgranular, granular and posterior agranular insular cortices) areas (Figure 2C), as well as into different cortical layers (Figure 2D). 
132 Subcortical structures, as for example, the hypothalamus (Figure 2E) and the hippocampus

133 (Figure 2F), were fully segmented according to Paxinos and Franklin's atlas ${ }^{27}$.

134

135

136

137

138

139

140

141

142

143

144

\section{Morphometric changes occurred during the gestation and lactation periods}

Next, we used our new resources to study the variations of GMC in mouse brain from the beginning of gestation until weaning. Using MRI $\mathrm{T}_{2}$-weighted anatomical acquisitions, we estimated the GMC maps which offer for each animal a global estimation of the GM. Longitudinal comparison of GMC between virgin mice (control group, $\mathrm{n}=11$ ) and mice who became pregnant and raised their young until weaning (parous group, $n=12$ ) permits to highlight local modifications of GM during the whole reproductive cycle. A comparison of baseline and early gestation GMC maps between the control and parous groups did not reveal significant differences. However, at the end of the gestation period, significant increases in GMC were observed within several brain regions in the parous group compared to the control group (Table S1 and Figure 3A). Time course analysis revealed differences in GMC profiles between control and parous groups at the end of the gestation period, early in lactation and at the end of the lactation period. Specifically, GMCs within the mPOA and the BNST were consistently significantly higher in the parous group at that times. In addition, within the agranular insular cortex in the late gestation period and the early lactation period, GMC was significantly higher in parous group compare to control group (Figure 4A). During the early lactation period, we also found specific and significant increases in GMCs of the parous group within numerous brain regions (Table S2 and Figure 3B). Among these structures, the hippocampus (CA1 layer), amygdalar area and piriform area showed a transient increase in GMC at the early lactation time point that returned to baseline values at the end of the lactation period in parous group compared to control group (Figure 4B). In contrast, the caudate putamen, arcuate nucleus and paraventricular nucleus of the hypothalamus (PVN) 
157 showed significantly higher GMCs in the parous mice than in the control mice during the lactation period (Table S3and Figures 3C and 4C). Together, our data demonstrate that the late gestation period is associated with a pronounced increase in GMC in the mPOA/BNST, the core neural system of maternal motivation, lasting up to the late lactation period. Furthermore, the early lactation period is associated with increased GMC in other key maternal motivation areas in midbrain regions, including the hypothalamus, caudate putamen and amygdala. These GMC differences between both groups were no longer observed after weaning.

\section{Morphometric changes during gestation predict the quality of maternal behavior}

In the last part of this work, we evaluated whether these morphometric changes might

reflect differences in maternal performance. Based on 15 min of behavioral observation during the pup retrieval test performed one week after birth, we evaluated the maternal performance of each mother by measuring the first, second and third pup retrieval times, pup-

171 licking duration, crouching time, rearing time, digging time and self-grooming time (Figure

5A). Interestingly, we observed a large distribution of values for both crouching (284.2 s, SD $\pm 268.7 \mathrm{~s})$ and digging $(98.22 \mathrm{~s}, \mathrm{SD} \pm 159.3 \mathrm{~s})$ durations within the parous group. Whereas crouching duration relates to maternal behavior, digging duration is widely recognized as a discriminative marker of stress-related behavior in rodents ${ }^{28}$. Hence, we used crouching and digging durations to cluster animals using the k-means clustering procedure, thereby clustering parous animals into a high maternal behavior group (those with a high crouching time and low digging time) and a low maternal behavior group (those with low crouching time and high digging time).

A comparison of maternal performance parameters between the two clustered 
digging time (Figure 5B) in the low maternal behavior group $(n=6)$ than in the high maternal behavior group $(\mathrm{n}=6)$. Moreover, a comparison of GMC maps revealed both cortical and subcortical differences between the two clustered groups, mainly in the late gestation period (Table S4 and Figure 5C) but also during the early lactation period (Table S5 and Figure 5D). Indeed, transient increases in GMCs within the entorhinal area, lateral part of the orbital area, $\mathrm{AOB}$, and medial preoptic area hat were observed at the end of pregnancy in the high maternal behavior group were absent in the low maternal behavior group (Figure 6A). In addition, the high maternal behavior group showed consistent higher GMCs in the hippocampus, retrosplenial area and barrel field of the primary somatosensory cortex (Figure 6B) from the end of the gestation until the end of the lactation period.

Interestingly, using a receiver operating characteristic (ROC) analysis, we found that GMCs values within the entorhinal area and $\mathrm{AOB}$ at late gestation are reliable predictors for mouse maternal performance after birth. These GMC values significantly distinguished low maternal performance from high maternal performance postpartum (entorhinal area: sensitivity $=100$, confidence interval $(\mathrm{CI})=61 \%$ to $100 \%$; specificity $=83, \mathrm{CI}=44 \%$ to 99\%; likelihood ratio $=6$; Figure 7A; AOB: sensitivity $=100, \mathrm{CI}=61 \%$ to $100 \%$; specificity $=83, \mathrm{CI}=44 \%$ to $99 \%$; likelihood ratio $=6$, Figure $7 \mathbf{B})$. The GMC values of both the entorhinal area and $\mathrm{AOB}$ observed at late gestation were also significantly correlated with maternal behavior (crouching and digging times). These results reveal that the GMC differences in olfactory (AOB and entorhinal cortex) and mnesic (entorhinal area)-related brain regions occurring during the late gestation period significantly predicted the quality of maternal behavior. 


\section{$\underline{\text { Discussion }}$}

Using a new comprehensive neuroimaging resource dedicated to mouse brain, this longitudinal study reveals that pregnancy and lactation coincide with pronounced and transient cerebral changes. Transient increases in GMCs were observed in key regions controlling maternal behavior (mPOA, BNST, and PVN), as well as regions involved in emotions (amygdala), in motivation and reward (caudate nucleus, orbitofrontal cortex) and in mnesic functions (hippocampus). Interestingly, increase in GMC was also revealed in the insular cortex thought to link social and emotional skills. Moreover, we showed that females expressing high levels of maternal behavior had developed specific increases in GMCs in structures involved in olfactory (MOB and $\mathrm{AOB}$ ) and somatosensory (somatosensory cortex) information processing, in memory (hippocampus, entorhinal cortex, retrosplenial cortex) and in reward and reinforcement (striatum). Interestingly, these hypertrophies were already significant at the end of the gestation period thus being predictive of the quality of maternal care (Supplemental Video 2).

\section{Implementation of new resources to support the analysis of mouse brain MRI data}

The use of preclinical MRI is a target of growing interest for the study of brain structure and function in both healthy and pathological conditions. The use of advanced MRI techniques, coupled with the development of advanced animal models, is a powerful way to push new breakthroughs in the understanding of brain functioning and pathology. Herein, in the first step in our study, from the recent major advances in the development of brain mouse atlas we generated a new set of neuroinformatic tools offering for the first time a complete resource dedicated to MRI studies of the mouse brain, namely, an accurate brain atlas (1320 ROIs), a high-resolution brain template and the associated GM, WM and CSF priors (60- $\mu \mathrm{m}$ isotropic resolution). The GM, WM and CSF probabilistic maps built and used in this study 
were calculated from $138 \mathrm{~T}_{2}$-weighted anatomical images, resulting in robust tissue class priors not only for VBM analysis but also for functional MRI and diffusion tensor imaging analysis in mice.

This comprehensive set of MRI compatible template and atlas for the mouse brain, allows a unified and standardized analysis of multimodal mouse brain MRI data and paves the way for the development of multicentric preclinical studies. Indeed, animal models deliver crucial information for the understanding of brain structure and function both in healthy and pathological conditions. Our template and mouse brain atlas were conceived to bridge the gap between basic and clinical neurosciences by providing to the preclinical neuroimaging community specific resources designed to be used in conjunction with the neuroinformatic tools and methodologies commonly used in human MRI studies. We anticipate that these resources will help neuroscientists to conduct their analyses of anatomical and functional datasets in a more standardized way, with the final goal of reaching more reproducible conclusions (https://www.nitrc.org/projects/tmbta_2019).

\section{Gestation and lactation periods induce strong but transient GMC hypertrophy}

The establishment of accurate mouse MRI resources permit to study the variations of GMC longitudinally, in vivo and during the gestation and lactation periods in female mice. We observed that several brain regions became transiently hypertrophic during pregnancy or in the lactation period until weaning. A set of structures comprising the core of the maternal circuit - especially the mPOA and BNST - displayed long-lasting hypertrophy that started at late gestation, culminated during the first week of lactation, and then disappeared at weaning. The initial GMC increase observed during the gestation period probably reflects changes induced by hormonal priming ${ }^{11}$. Indeed, both the mPOA and BNST express a high number of steroid hormone and neuropeptide receptors ${ }^{29,30}$. These factors are well known to trigger 
254 significant plasticity changes within the core maternal circuitry that are necessary for the 255 preparation and adaptation of the brain to motherhood $^{3,11}$. From parturition, the GMC 256 differences observed during the whole lactation period highlight that mPOA/BNST receives a 257 variety of sensory inputs from the pups, integrates that information with the females' endocrine status, and then projects to brain sites involved in socially-relevant motivation,

259 affective state, and cognition ${ }^{2,31}$. Pup stimulation, electrolytic and neurotoxic lesions and local 260 steroid hormone injections ${ }^{32-35}$ have been shown to modify the intrinsic activity of these 261 nuclei and consequently responsible for motivation and expression of maternal behavior. The mPOA is engaged throughout the postpartum period but differentially according to the needs of the developing pups. It has been shown that neurons of the mPOA in late postpartum inhibits maternal responses allowing the changing expression and waning of maternal behavior across postpartum ${ }^{10}$. The sustained increase in GMC reported in late lactation could reflect the involvement of the mPOA to appropriately influence maternal behavior.

267 Our study highlights another set of brain structure that became hypertrophic only during the period from parturition to weaning - specifically, the PVN and arcuate nucleus of the hypothalamus. These changes illustrate the structural plasticity occurring in these regions. dramatic neuronal, glial and synaptic changes such as an increase in size of the oxytocin

272 neurons and an amplification of their synaptic input ${ }^{36}$. Oxytocin release at parturition 273 facilitates the onset of maternal behavior by acting on the mPOA and is also important for 274 maternal memory ${ }^{37}$. Finally, lesions of the PVN disrupt the onset of maternal behavior ${ }^{38-40}$. In 275 the arcuate nucleus, dopaminergic cells are responsible for suckling induced prolactin 276 release $^{41}$ and neurons projecting to the arcuate nucleus are involved in the maintenance of 277 maternal motivation ${ }^{42}$. 
Additionally, we report changes in GMCs found in olfactory related structures (main

olfactory bulb, piriform cortex), somatosensory areas and auditory areas which reflect the

multisensory control of maternal behavior. This finding is in accordance with a functional

MRI study performed in rats which demonstrates that pup suckling is associated with

increased neuronal activity within the midbrain, striatum and cortical sensory areas (somatosensory, olfactory and auditory cortices) ${ }^{9}$.

GMC variations within the hippocampus and entorhinal cortex, highlight the role of

two essential structures involved in learning and memory processing during the reproductive

period. Our data support evidence that the hippocampus undergoes profound neural changes

287 during lactation. Indeed, lactating females have elevated spine densities in the hippocampus ${ }^{43}$

neurogenesis occurs during lactation and may support the enhancement of spatial memory necessary to foraging behavior in lactating females ${ }^{43,45-47}$.

Finally, our study also revealed a hypertrophy of the agranular insular cortex, which

has never been reported in this context. The agranular insular cortex is a laminar part of the insular cortex and can be considered as a hub structure linking large-scale brain systems ${ }^{48}$.

Indeed, the insula receives direct thalamic and somatosensory afferents carrying sensitive with the limbic system (basolateral, lateral and central amygdalar nuclei) as well as with the

BNST, mediodorsal nucleus of the thalamus, lateral hypothalamus and perirhinal and lateral entorhinal cortices ${ }^{48}$. The insula also connects brain regions implicated in motivation and

299 reward, such as the nucleus accumbens and caudate putamen ${ }^{48}$. Hence, our findings and the 
neurophysiological adaptation occurring in the brain from the early gestation period to weaning, thereby ensuring efficient maternal behavior and, by extension, the development of the offspring.

\section{GMC modifications in the olfactory system at the end of the gestation predict the level of}

\section{maternal behavior post-partum}

All these transient modifications of GMC in parous animals indicate that various brain regions undergo considerable plasticity from birth to weaning. Then, we sought to determine whether inter-individual variations in maternal behavior were associated with similar variations of GMC. Based on their behavioral performance in the pup retrieval test, we used a k-means clustering strategy to divide maternal female mice into two groups displaying high versus low levels of maternal behavior. This analysis revealed that several transient and several long-lasting increases in GMCs were observed in the high maternal behavior group that were absent in the low maternal behavior group. Brain regions showing significant differences included the olfactory bulbs, somatosensory system, limbic system, especially the orbitofrontal area, and mnesic system, including the retrosplenial cortex, hippocampus and entorhinal area. Some of these structures are directly responsive to pup stimulation, and the observed dynamics may have been induced by mother-offspring interactions. For example, higher GMC values in the somatosensory cortex and olfactory bulbs in the high maternal behavior group potentially reflected increased suckling duration and proximity between the mother and pups, respectively.

Strikingly, differences in GMCs were detected in the entorhinal area, orbitofrontal area, olfactory bulb, hippocampus, retrosplenial area and primary somatosensory area before parturition. These findings suggest that the maturation of these structures, probably through hormone-dependent plasticity mechanisms, is a key determinant of the intensity of maternal behavior expressed during the lactation period. Using a ROC procedure, we found that GMC 
values of the entorhinal area and $\mathrm{AOB}$ at the end of gestation were significantly predictive of the maternal behavior postpartum. Interestingly, previous studies in mice reported an increase in cell proliferation during gestation in the subventricular zone, the neurogenic niche which provides newly generated neurons within the olfactory bulb (for review see ${ }^{13}$ ). These adultborn olfactory neurons are fully responsive to pup odor exposure ${ }^{49}$ and are in part involved in some components of maternal behavior ${ }^{50,51}$.

Hence, the correlations observed between GMC values in $\mathrm{AOB}$ at the late gestation period and maternal behavior performances may suggest that impairments of neural plasticity of this olfactory region would induce maladaptive neuroendocrine processing of the maternal brain at the end of the gestation period impacting maternal behavior performance. Taken together, our data provide the first potential imaging-based predictive biomarkers of the quality of maternal behavior and suggest the key role of the maturation of the olfactory system at the end of the pregnancy in the development of adaptative maternal behavior in mice.

\section{Conclusion}

Our study provides a new generation of neuroinformatic tools which will help basic neuroscientists to conduct structural and functional MRI investigations. Using these resources, we found that the development of the maternal brain is associated with substantial mesoscopic changes in critical regions. These modifications can be interpreted as cell size changes, neural or glial cell genesis/apoptosis, spine density or blood flow modifications ${ }^{52-54}$. As cellular and molecular plasticity events are key for the adaptation of the brain to motherhood, molecular, cellular and behavioral investigations must be performed to obtain a more precise view of the physiological mechanisms responsible for GMC variations. 
352

353

354

355

356

357

358

359

360

361

362

\section{$\underline{\text { Methods }}$}

Animals. Twenty-three female RjOrl:SWISS virgin mice (8 weeks old; 20-25 g; Janvier Laboratory, Le Genest-Saint-Isle, France) were maintained on a 12-h light/dark cycle with access to food (standard chow) and water ad libitum. Animals were acclimatized 6 per cage to the housing facility for 7 days prior to manipulation. Females were randomly divided into two groups: a parous group $(n=12)$, in which each female was exposed to a male (RjOrl:SWISS,8 weeks old; 20-25 g; Janvier Laboratory, Le Genest-Saint-Isle, France) for 5 days, became pregnant, and raised their offspring (litter size: 6 to 14 pups) until weaning at 21 days postpartum, and a control group $(\mathrm{n}=11)$, in which virgin females were not exposed to male mice. Each parous female was individually housed after male exposure. Control females were housed together in a separate room from parous females.

The MRI protocol was optimized to keep mice anesthetized for $2 \mathrm{~h}$ during each of the six acquisitions. During lactation MRI acquisitions, pups were kept under a heat lamp. One week after birth, maternal behavior was assessed as described in the behavioral section. All experiments were conducted in accordance with the local research ethics committee (APAFIS \#6626-201002281145814V1) and are reported in accordance with the ARRIVE guidelines.

MRI acquisition. In vivo 3D MRI of the entire brain was performed three days before male exposure (baseline), at one week of gestation (early gestation), two days before the expected day of birth (late gestation), one week postpartum (early lactation), three weeks postpartum (late lactation) and two weeks after weaning (weaning). One female in the parous group and one female in the control group were scanned under similar conditions on the same day.

Mice were anesthetized using isoflurane (2.5\%; induction in $\mathrm{O}_{2}$ /air mixture 1:1) (TEM-SEGA, F-33600 Pessac, France) and then transferred and placed head first procubitus within an MRI-compatible cradle that incorporated a stereotaxic system dedicated for mouse 
377 head MRI, connected to a heater with circulating water to maintain body temperature and supplied with $1-2 \%$ isoflurane via a fitted mask. Respiration rate was recorded during all the experiments using an MRI-compatible monitoring system (PC-SAM model \#1025; SA Instruments Inc., Stony Brook, NY, USA) and used to adjust the isoflurane rate to maintain a rate between 20 and 40 respirations per minute. After a recovery period of one hour, mouse returned to her pups. MRI studies were conducted at the Centre de Biophysique Moléculaire d'Orléans and were performed on a 7T/160 mm PharmaScan spectrometer (Bruker Biospin, Wissembourg, France) equipped with an actively shielded B-GA09 gradient set, with 90-mm inner diameter and 300-mT/m gradient intensity. A 23-mm inner diameter Bruker birdcage coil with a cradle dedicated to a mouse head was used. Data acquisitions were performed on an Advance III console running ParaVision 5.1 software. $\mathrm{T}_{2}$-weighted images were acquired using a 3D fast large-angle spin-echo (FLASE) sequence which allows 3D brain mapping with a high resolution in a suitable time for in vivo acquisition ${ }^{55,56}$. Thus, the sequence with echo time $(\mathrm{TE})=20 \square \mathrm{ms}, 1$ repetition, acquisition matrix $=160 \times 140 \times 95$, and a field of view $(\mathrm{FoV})$ of $19.2 \times 16.8 \times 11.4 \square \mathrm{mm}^{3}$, resulting in a final resolution of $120 \mu \mathrm{m}$ isotropic voxels $^{55,56}$. To obtain the FLASE sequence ${ }^{55}$, which is a specific sequence that is not included in the sequence package provided with ParaVision, the usual rapid acquisition with relaxation enhancement (RARE) spin-echo sequence was modified; in particular, the RARE-factor was fixed to 1 allowing a flip angle (FA) higher than $90^{\circ}$ for the excitation pulse, while maintaining a $180^{\circ}$ refocusing pulse ${ }^{55}$. Thus, $\mathrm{T}_{2}$-weighted images were obtained with a repetition time (TR) as short as $300 \square \mathrm{ms}, 10$ times lower than that needed for a classical $\mathrm{T}_{2}-$ weighted spin-echo sequence. The sequence was optimized for acquisition in 1 h 28 min, with an isotropic resolution of $120 \mu \mathrm{m}$, a TR of $300 \mathrm{~ms}$, an TE of $20 \mathrm{~ms}$, an excitation pulse (FA) 
402 Maternal behavioral test. One week after birth, the maternal behavior of each female was

403 evaluated using the pup retrieval test ${ }^{57}$. Briefly, three pups were removed from the nest and

404 placed at three different corners within the home cage. The latency to retrieve each pup and

405 the time spent licking the pups, crouching in the nest over the pups and performing

406 nonmaternal behaviors such as self-grooming and digging were recorded over $15 \mathrm{~min}$.

407 Retrieval was defined as the animal picking up a pup and transporting it to the nest.

408 Crouching was defined as the animal assuming the nursing posture. Nursing and licking were

409 permitted whether they took place in the nest. All videos were analyzed using BORIS

$410 \quad$ software version 4.1.4.

K-means clustering. Clustering analysis of the behavioral data was performed using

MATLAB Simulink 10b (The Mathworks, Inc., USA). Normality was verified and no outlier subjects were detected. To classify animals according to their maternal performance, a kmeans clustering algorithm was used with crouching and digging times as behavioral markers.

416 Digging was chosen because it is indicative of high maternal stress ${ }^{28,58}$. This algorithm

417 iteratively grouped the animals by creating $\mathrm{k}$ initial centroids, assigning each animal to the closest centroid, iteratively re-calculating the centroids from the mean of its assigned animals and re-assigning the animals to each centroid until there were no more changes across iterations $^{59}$. This clustering divided parous animals into a high maternal behavior group (with

421 high crouching and low digging time) and low maternal behavior group (with low crouching and high digging time).

Mouse brain template and atlas building. For the MRI protocol, we developed a brain 
427 template and its associated atlases and the Allen Mouse Brain Atlas and its associated Nissl

428 images to a suitable resolution for MRI analysis $(60-\mu \mathrm{m}$ isotropic resolution; Figure 1, step

429 1). Then, all images were manually aligned to the anterior commissure/posterior commissure

430 (AC/PC) axis, and the center of the images was defined relative to the AC (Figure 1, step 2).

431 The resulting template was then segmented into GM, WM and CSF probability maps using

432 the unified segmentation approach $^{60}$ of Statistical Parametric Mapping 8 (SPM8) and the

433 mouse brain priors provided by the SPMMouse toolbox (Figure 1, step 3). In parallel, our $\mathrm{T}_{2}$ -

434 weighted anatomical images were realigned, coregistered, bias-corrected and normalized to

435 our template. Using the SPMMouse toolbox, we also segmented the images as described

436 above, and from these preprocessed images, we obtained a large set of 138 images for each

437 tissue class (Figure 1, steps 4-7). From these images, we built population-specific GM, WM

438 and CSF priors. To build these priors, for each tissue class, we applied a diffeomorphic

439 anatomical registration using an exponentiated lie algebra (DARTEL) approach, which is an

440 automated, unbiased, and nonlinear template-building algorithm ${ }^{61}$ (Figure 1, step 8). This

441 new set of population-specific tissue priors was used for both atlas building and final VBM

442 preprocessing.

443 To normalize the Allen Mouse Brain Atlas to our brain template, we used the 444 associated Nissl-stained images because (1) Nissl staining corresponds to the GM prior in 445 terms of histology, and (2) this image was already coregistered to the atlas (Figure 1, step 4).

446 Therefore, we applied the segmentation function provided by SPM8 using the GM prior 447 previously calculated from the Nissl image to generate the "Nissl2template" normalization 448 matrix. We used this matrix to normalize the atlas to the template, while avoiding 449 interpolation to maintain the label indices as integers (Figure 1, step 7). Then, a visual 450 inspection of each normalized label was carried out to assess whether the normalization 451 process modified the position and volume of the structure too much. When necessary, holes 
452 were filled and labels were redrawn according to Paxinos and Franklin's atlas and using the

453 FreeSurfer package. Finally, the olfactory bulbs and hind brain regions were completed, the

454 corpus collosum and ventricles were drawn from the WM and CSF priors, and the cerebellum

455 labels were replaced by the AMBMC cerebellum labels, which are more accurate. Finally, the

456 atlas image was symmetrized (left-right). Our mouse brain template, priors and atlas were

457 normalized within the same space and with the same final resolution $(60-\mu \mathrm{m}$ isotropic

458 resolution), resulting in our final mouse brain atlas composed of a mosaic of 1320 ROIs

459 covering the entire brain (Supplemental Video 1).

VBM data preprocessing. Previously preprocessed normalized $\mathrm{T}_{2}$-weighted data were

priors (Figure 1, step 9). Then, to produce a more accurate registration within each mouse as

well as across all mice, a longitudinal VBM analysis was applied using the strategy described

by Asami et $a l^{62}$. First, a subject-specific template was created by the DARTEL algorithm

using the previous tissue class images (i.e., GM, WM, and CSF maps) obtained from each

mouse for the six time points. The DARTEL procedure releases individual-specific flow field normalized tissue class image was modulated by the Jacobian determinant to account for the expansion and/or contraction of brain regions over time. Then, a population-specific template

472 was created by the DARTEL algorithm using all subject-specific templates of the tissue class images. Here, the DARTEL procedure releases population-specific flow field maps, 
477 kernel with a 3-mm full-width at half-maximum and convolved with GMC images to create

478 GMC maps (Figure 1, steps 10-12).

479 VBM statistics and analysis. SPM8 was used to reveal the temporal and regional changes in 480 the GMC maps. A second-level SPM analysis comprising a flexible factorial model, which is 481 equivalent to a $2 \times 2$ mixed-model ANOVA with group as the between-subject factor and time 482 point as the within-subject factor, was used to compare the control versus the parous groups 483 and the low versus high maternal behavior groups ${ }^{63}$. The factors included in the analysis were 484 subjects, group (control versus parous, or low maternal behavior versus high maternal behavior), and time points (baseline, early gestation, late gestation, early lactation, late gestation, and weaning). A brain mask was used to constrain the analysis within the brain. For each cluster, the significance of the peak voxel was set as $p<0.01\left(\mathrm{t}_{(126)}=2.356\right.$, control versus parous; $\mathrm{t}_{(60)}=2.39$, low versus high maternal behavior), and the minimum cluster extent was set at 25 voxels. The results are presented on axial brain slice series generated by the $\underline{\text { Xjview }}$ SPM plugin. Corresponding surfacing results were produced with $\underline{\text { BrainNet }}$ viewer $1.6^{64}$, allowing the generation of both brain meshes and brain plots to visualize data and create supplemental videos.

Postprocessing statistical analysis. Cluster peaks revealed by the flexible factorial analyses were identified using our atlas and an in situ procedure developed with MATLAB Simulink 10b (The Mathworks, USA). For each comparison, clusters were binarized, and the obtained masks were used to extract GMC values of corresponding regions from the GMC map using the REX plugin. GMC data and behavioral measurements were then compiled and analyzed using GraphPad Prism 6.02 software. GMCs were compared between groups and for each

500 time point using a two-way ANOVA with repeated measures followed by a two-stage setup 501 method of Benjamini, Kriegger and Yekutieli as recommended by the software. Maternal and 
502 nonmaternal behaviors of the low maternal and high maternal groups were compared using a

503 multicomparison t-test with a false discovery rate (FDR) approach $(\mathrm{Q}=1 \%)$. Correlation

504 analyses were performed using a parametric two-tailed Pearson test. Specificity and

505 selectivity analyses were performed using the ROC curve method. Statistical significance was

506 defined as $\mathrm{p}<0.05(*)$ for these analyses. 


\section{Acknowledgments}

508 The authors acknowledge the regional council of Centre Val-de-Loire for funding this

509 research through the IMACERVOREPRO grant (convention 201500104011, 2015-2018)

510 awarded to Matthieu Keller.

511

\section{Author Contributions}

513 D.A.B. contributed to the atlas and template building, data analysis, drafted and revised the

514 manuscript. A.E. contributed to the imaging sequence troubleshooting, data analysis and 515 contributed to the critical revisions. F.S. contributed to MRI sequence programming, imaging 516 protocol setting, data acquisitions and contributed to the analysis and critical revisions. H.A.,

517 W.M., E.C., M.M., S.M. contributed to the study conception and design and contributed to 518 the critical revisions of the manuscript. F.L. contributed to raise the funding, study conception 519 and design and contributed to the critical revisions of the manuscript. M.K., is the principal 520 investigator of the study, raised the funding, coordinated the project, revised and validated the 521 manuscript. 
522

523

524

525

526

527

528

529

530

531

532

533

534

535

536

537

538

539

540

541

542

543

544

545

546

547

548

549

550

551

552

553

554

555

556

557

558

559

560

561

562

563

564

565

566

567

568

569

570

571

572

573

574

\section{References}

1. Numan, M. \& Insel, T. R. The neurobiology of parental behavior. (Springer, 2003).

2. Lonstein, J. S., Lévy, F. \& Fleming, A. S. Common and divergent psychobiological mechanisms underlying maternal behaviors in non-human and human mammals. Horm. Behav. 73, 156-185 (2015).

3. Bridges, R. S. Neuroendocrine regulation of maternal behavior. Front. Neuroendocrinol. 36, 178-196 (2015).

4. Kohl, J. \& Dulac, C. Neural control of parental behaviors. Curr. Opin. Neurobiol. 49, 116-122 (2018).

5. Kohl, J., Autry, A. E. \& Dulac, C. The neurobiology of parenting: A neural circuit perspective. BioEssays 39, e201600159 (2017).

6. Lévy, F. \& Keller, M. Olfactory mediation of maternal behavior in selected mammalian species. Behav. Brain Res. 200, 336-345 (2009).

7. Numan, M. \& Stolzenberg, D. S. Medial preoptic area interactions with dopamine neural systems in the control of the onset and maintenance of maternal behavior in rats. Front. Neuroendocrinol. 30, 46-64 (2009).

8. Afonso, V. M., Sison, M., Lovic, V. \& Fleming, A. S. Medial prefrontal cortex lesions in the female rat affect sexual and maternal behavior and their sequential organization. Behav. Neurosci. 121, 515-526 (2007).

9. Febo, M. A bold view of the lactating brain: functional magnetic resonance imaging studies of suckling in awake dams. J. Neuroendocrinol. 23, 1009-1019 (2011).

10. Pereira, M. \& Morrell, J. I. Functional Mapping of the Neural Circuitry of Rat Maternal Motivation: Effects of Site-Specific Transient Neural Inactivation: Mapping maternal motivation circuitry. J. Neuroendocrinol. 23, 1020-1035 (2011).

11. Brunton, P. J. \& Russell, J. A. The expectant brain: adapting for motherhood. Nat. Rev. Neurosci. 9, 11-25 (2008).

12. Kinsley, C. H. \& Lambert, K. G. Reproduction-Induced Neuroplasticity: Natural Behavioural and Neuronal Alterations Associated with the Production and Care of Offspring. J. Neuroendocrinol. 20, 515-525 (2008).

13. Lévy, F., Gheusi, G. \& Keller, M. Plasticity of the Parental Brain: A Case for Neurogenesis: Parental behaviour and neurogenesis. J. Neuroendocrinol. 23, 984-993 (2011).

14. Akbari, E. M., Chatterjee, D., Lévy, F. \& Fleming, A. S. Experience-dependent cell survival in the maternal rat brain. Behav. Neurosci. 121, 1001-1011 (2007).

15. Hoekzema, E. et al. Pregnancy leads to long-lasting changes in human brain structure. Nat. Neurosci. 20, 287 (2017).

16. Kohl, J. et al. Functional circuit architecture underlying parental behaviour. Nature 556, 326-331 (2018).

17. Ashburner, J. \& Friston, K. J. Unified segmentation. NeuroImage 26, 839-851 (2005).

18. Sawiak, S. J., Wood, N. I., Williams, G. B., Morton, A. J. \& Carpenter, T. A. Voxel-based morphometry with templates and validation in a mouse model of Huntington's disease. Magn. Reson. Imaging 31, 1522-1531 (2013).

19. Sawiak, S. J., Picq, J.-L. \& Dhenain, M. Voxel-based morphometry analyses of in vivo MRI in the aging mouse lemur primate. Front. Aging Neurosci. 6, (2014).

20. Keifer Jr, O. P. et al. Voxel-based morphometry predicts shifts in dendritic spine density and morphology with auditory fear conditioning. Nat. Commun. 6, (2015).

21. Lein, E. S. et al. Genome-wide atlas of gene expression in the adult mouse brain. Nature 445, 168-176 (2007).

22. Ullmann, J. F. P. et al. Segmentation of the C57BL/6J mouse cerebellum in magnetic resonance images. NeuroImage 62, 1408-1414 (2012).

23. Richards, K. et al. Segmentation of the mouse hippocampal formation in magnetic resonance images. NeuroImage 58, 732-740 (2011).

24. Watson, C. et al. An ontologically consistent MRI-based atlas of the mouse diencephalon. NeuroImage 157, 275-287 (2017).

25. Ullmann, J. F. P., Watson, C., Janke, A. L., Kurniawan, N. D. \& Reutens, D. C. A segmentation protocol and MRI atlas of the C57BL/6J mouse neocortex. Neurolmage 78, 196-203 (2013).

26. Wang, Q. et al. The Allen Mouse Brain Common Coordinate Framework: A 3D Reference Atlas. Cell 181, 936-953.e20 (2020).

27. Paxinos and Franklin's the Mouse Brain in Stereotaxic Coordinates, Compact - 5th Edition. https://www.elsevier.com/books/paxinos-and-franklins-the-mouse-brain-in-stereotaxic-coordinates-

compact/franklin/978-0-12-816159-3. 
28. Deacon, R. M. J. Digging and marble burying in mice: simple methods for in vivo identification of biological impacts. Nat. Protoc. 1, 122 (2006).

29. Tsuneoka, Y. et al. Neurotransmitters and neuropeptides in gonadal steroid receptor-expressing cells in medial preoptic area subregions of the male mouse. Sci. Rep. 7, 1-16 (2017).

30. McHenry, J. A., Rubinow, D. R. \& Stuber, G. D. Maternally responsive neurons in the bed nucleus of the stria terminalis and medial preoptic area: Putative circuits for regulating anxiety and reward. Front. Neuroendocrinol. 38, 65-72 (2015).

31. Olazábal, D. E. et al. Flexibility and adaptation of the neural substrate that supports maternal behavior in mammals. Neurosci. Biobehav. Rev. 37, 1875-1892 (2013).

32. Bridges, R. S. \& Hays, L. E. Steroid-induced alterations in mRNA expression of the long form of the prolactin receptor in the medial preoptic area of female rats: Effects of exposure to a pregnancy-like regimen of progesterone and estradiol. Brain Res. Mol. Brain Res. 140, 10-16 (2005).

33. Lonstein, J. S. \& De Vries, G. J. Maternal behaviour in lactating rats stimulates c-fos in glutamate decarboxylase-synthesizing neurons of the medial preoptic area, ventral bed nucleus of the stria terminalis, and ventrocaudal periaqueductal gray. Neuroscience 100, 557-568 (2000).

34. Miceli, M. O., Fleming, A. S. \& Malsbury, C. W. Disruption of maternal behaviour in virgin and postparturient rats following sagittal plane knife cuts in the preoptic area-hypothalamus. Behav. Brain Res. 9, 337-360 (1983).

35. Lee, A., Clancy, S. \& Fleming, A. S. Mother rats bar-press for pups: effects of lesions of the mpoa and limbic sites on maternal behavior and operant responding for pup-reinforcement. Behav. Brain Res. 100, 15-31 (1999).

36. El Majdoubi, M., Poulain, D. A. \& Theodosis, D. T. Activity-dependent morphological synaptic plasticity in an adult neurosecretory system: magnocellular oxytocin neurons of the hypothalamus. Biochem. Cell Biol. Biochim. Biol. Cell. 78, 317-327 (2000).

37. D'Cunha, T. M., King, S. J., Fleming, A. S. \& Lévy, F. Oxytocin receptors in the nucleus accumbens shell are involved in the consolidation of maternal memory in postpartum rats. Horm. Behav. 59, 14-21 (2011).

38. Insel, T. R. \& Harbaugh, C. R. Lesions of the hypothalamic paraventricular nucleus disrupt the initiation of maternal behavior. Physiol. Behav. 45, 1033-1041 (1989).

39. Numan, M. \& Corodimas, K. P. The effects of paraventricular hypothalamic lesions on maternal behavior in rats. Physiol. Behav. 35, 417-425 (1985).

40. Olazábal, D. E., Kalinichev, M., Morrell, J. I. \& Rosenblatt, J. S. MPOA cytotoxic lesions and maternal behavior in the rat: effects of midpubertal lesions on maternal behavior and the role of ovarian hormones in maturation of MPOA control of maternal behavior. Horm. Behav. 41, 126-138 (2002).

41. Freeman, M. E., Kanyicska, B., Lerant, A. \& Nagy, G. Prolactin: structure, function, and regulation of secretion. Physiol. Rev. 80, 1523-1631 (2000).

42. Cservenák, M. et al. Thalamic neuropeptide mediating the effects of nursing on lactation and maternal motivation. Psychoneuroendocrinology 38, 3070-3084 (2013).

43. Kinsley, C. H. et al. Motherhood and the hormones of pregnancy modify concentrations of hippocampal neuronal dendritic spines. Horm. Behav. 49, 131-142 (2006).

44. Pawluski, J. L. \& Galea, L. A. M. Hippocampal morphology is differentially affected by reproductive experience in the mother. J. Neurobiol. 66, 71-81 (2006).

45. Pawluski, J. L., Walker, S. K. \& Galea, L. A. M. Reproductive experience differentially affects spatial reference and working memory performance in the mother. Horm. Behav. 49, 143-149 (2006).

46. Eid, R. S. et al. Early and late effects of maternal experience on hippocampal neurogenesis, microglia, and the circulating cytokine milieu. Neurobiol. Aging 78, 1-17 (2019).

47. Duarte-Guterman, P., Leuner, B. \& Galea, L. A. M. The long and short term effects of motherhood on the brain. Front. Neuroendocrinol. 53, 100740 (2019).

48. Gogolla, N. The insular cortex. Curr. Biol. 27, R580-R586 (2017).

49. Mak, G. K. \& Weiss, S. Paternal recognition of adult offspring mediated by newly generated CNS neurons. Nat. Neurosci. 13, 753-758 (2010).

50. Larsen, C. M. \& Grattan, D. R. Prolactin-induced mitogenesis in the subventricular zone of the maternal brain during early pregnancy is essential for normal postpartum behavioral responses in the mother. Endocrinology 151, 3805-3814 (2010).

51. Sakamoto, M. et al. Continuous neurogenesis in the adult forebrain is required for innate olfactory responses. Proc. Natl. Acad. Sci. U. S. A. 108, 8479-8484 (2011). 
629 52. Kelly, J. R. et al. Breaking down the barriers: the gut microbiome, intestinal permeability and stress-related psychiatric disorders. Front. Cell. Neurosci. 9, 392 (2015).

631 53. Arentsen, T. et al. The bacterial peptidoglycan-sensing molecule Pglyrp2 modulates brain development and behavior. Mol. Psychiatry 22, 257-266 (2017). 54. Barrière, D. A. et al. Structural and functional alterations in the retrosplenial cortex following neuropathic pain. Pain (2019) doi:10.1097/j.pain.0000000000001610. 55. DiIorio, G., Brown, J. J., Borrello, J. A., Perman, W. H. \& Shu, H. H. Large angle spin-echo imaging. Magn. Reson. Imaging 13, 39-44 (1995).

56. Ma, Y. et al. In vivo 3D digital atlas database of the adult C57BL/6J mouse brain by magnetic resonance microscopy. Front. Neuroanat. 2, (2008).

639 57. Keller, M., Pawluski, J. L., Brock, O., Douhard, Q. \& Bakker, J. The $\alpha$-fetoprotein knock-out mouse model 640 suggests that parental behavior is sexually differentiated under the influence of prenatal estradiol. Horm. Behav. $64157,434-440(2010)$.

642 58. van den Brom, C. E. et al. Altered myocardial substrate metabolism is associated with myocardial 643 dysfunction in early diabetic cardiomyopathy in rats: studies using positron emission tomography. Cardiovasc. 644 Diabetol. 8, 39 (2009).

645 59. Magalhães, R. et al. The dynamics of stress: a longitudinal MRI study of rat brain structure and connectome. 646 Mol. Psychiatry (2017) doi:10.1038/mp.2017.244.

647 60. Ashburner, J. \& Friston, K. J. Voxel-based morphometry--the methods. NeuroImage 11, 805-821 (2000).

648 61. Ashburner, J. A fast diffeomorphic image registration algorithm. NeuroImage 38, 95-113 (2007).

649 62. Asami, T. et al. Longitudinal loss of gray matter volume in patients with first-episode schizophrenia: DARTEL automated analysis and ROI validation. NeuroImage 59, 986-996 (2012).

651 63. Barrière, D. A. et al. In vivo magnetic resonance imaging reveals the effect of gonadal hormones on 652 morphological and functional brain sexual dimorphisms in adult sheep. Psychoneuroendocrinology 109, 104387 653 (2019).

654 64. Xia, M., Wang, J. \& He, Y. BrainNet Viewer: a network visualization tool for human brain connectomics. 655 PloS One 8, e68910 (2013). 
bioRxiv preprint doi: https://doi.org/10.1101/2020.05.23.112045; this version posted June 19,2020. The copyright holder for this preprint (which was not certified by peer review) is the author/funder, who has granted bioRxiv a license to display the preprint in perpetuity. It is made available under aCC-BY-ND 4.0 International license.

$\underline{\text { Tables }}$

\begin{tabular}{|c|c|c|c|c|c|c|c|c|c|c|c|c|}
\hline $\begin{array}{l}\text { Ex rivo/ } \\
\text { In vive }\end{array}$ & Strain & Scx & $\begin{array}{l}\text { Age } \\
\text { (days) }\end{array}$ & $\begin{array}{c}\text { Number of } \\
\text { animals }\end{array}$ & $\begin{array}{c}\text { Magnetic field } \\
\text { iniensity }\end{array}$ & $\begin{array}{c}\text { Anatomical } \\
\text { contrast }\end{array}$ & $\begin{array}{c}\text { Spatial } \\
\text { resolution }\end{array}$ & $\begin{array}{c}\text { MRI } \\
\text { Template }\end{array}$ & Athas & $\begin{array}{l}\text { Regions } \\
\text { of interest }\end{array}$ & $\begin{array}{c}\text { Tlisule } \\
\text { Probabififty } \\
\text { maps }\end{array}$ & Referenees \\
\hline$L x$ vivo & $(S / 1 \mathrm{~L} /(6)$ & Male & 63 & 6 & 9.4 Tesla & $\begin{array}{l}\mathrm{T}, \\
P D \\
\mathrm{PW}\end{array}$ & 9n $\times 90 \times 9 n$ & Yes & Yes & 21 & No & $\begin{array}{l}\text { Alu at al, } \\
2005\end{array}$ \\
\hline In พxiv & (c57pi)/6) & Male & 100 & 6 & 11.7 Tesla & $\mathrm{T}$, & (9) $\underset{\mu \mathrm{m}^{2}}{\mathrm{2}} 60 \mathrm{x}$ & Yes & Yes & $\mathrm{NA}$ & No & $\begin{array}{c}\text { MarKensie-Grahun et } \\
\text { al, } x o m\end{array}$ \\
\hline Txuvo & $120 \mathrm{~S} 1 / \mathrm{SvTmJ}$ & Mals & 56 & $\stackrel{\circ}{\circ}$ & 7 Tesla & $\mathrm{T}_{2}$ & $\log _{\mu m^{3}}^{600} 60$ & Yos & Yes & 9 & No & Kmalevió at al, 20005 \\
\hline$L x$ wivo & $(5 / 1 L / 6)$ & $\mathrm{N} \Lambda$ & fo & 8 & 11./ Iesla & Ir, & $\begin{array}{c}40 \times 40 \times 40 \\
1 \mathrm{~m}^{3}\end{array}$ & Yes & Yes & 12 & Yes & $\begin{array}{l}\text { lecetal. } \\
2005\end{array}$ \\
\hline Invono & C5TBT/GJ & Male & 8498 & 12 & 2.4 Tesla & $\mathrm{T}_{2}$ & $\begin{array}{c}1(x) \times 100 \times 100 \\
1 \mathrm{~m}^{3}\end{array}$ & Yes & Yes & 20 & No & $\begin{array}{l}\text { Mo et at, } \\
\text { zous }\end{array}$ \\
\hline In vovy & $(311 / 1$ esin) & $\mathrm{NA}$ & II & 16 & Tlesla & Ii & $\underset{156 \times 156 i \times 156}{\mu \mathrm{m}^{2}}$ & Yes & Yes & 6 & No & $\begin{array}{c}\text { Find wial } \\
2006\end{array}$ \\
\hline Kx vivo & $\begin{array}{c}129 \mathrm{~S} 1 / \mathrm{SuTmJ} \\
\mathrm{C} 557 / \mathrm{BIG} \\
\mathrm{CTII}\end{array}$ & Male & 126 & 27 & 7 Tessla & $\mathrm{T}_{2}$ & $\begin{array}{c}60 \times 60 \times 60 \\
\mu m^{3}\end{array}$ & Yes & Yes & 12 & No & $\begin{array}{c}\text { Chen et al. } \\
20008\end{array}$ \\
\hline Fix vivo & $(57+31 / 6)$ & $\mathrm{NA}$ & 6.3 & 6 & 9.4 Tesla & $\begin{array}{l}\mathrm{T}_{1} \\
\mathrm{~T}_{2}\end{array}$ & $\begin{array}{c}21 \times \times 2.1 \times 3 \times 21 \\
\mu \mathrm{m}^{3} \\
43 \times 43 \times 43 \\
\mu \mathrm{m}^{3}\end{array}$ & Yes & Yes & 3.3 & No & $\begin{array}{l}\text { Busleuet ah } \\
\text { zous }\end{array}$ \\
\hline$L x$ vivo & $\cos \pi \mathrm{s} / \mathrm{s} \mathrm{S}$ & $\begin{array}{c}20 \text { males } \\
20 \text { temales }\end{array}$ & 84 & 4) & Tlesla & 1 , & $\begin{array}{c}32 \times 32 \times 32 \\
\mu \mathrm{m}^{3}\end{array}$ & Yes & Yes & 62 & No & $\begin{array}{l}\text { Dorr et al, } \\
200 s\end{array}$ \\
\hline Lx vivo & $\begin{array}{c}(\text { S } / 13 / / 6) \\
\text { and } \\
\text { BXI) }\end{array}$ & Malc & 63 & 12 & 9.4 Tesla & $\begin{array}{l}\mathrm{T}_{1} \\
\mathrm{~T}_{2}\end{array}$ & $\begin{array}{c}21.5 \times 21.5 \times 21.5 \\
\mu \mathrm{m}^{3} \\
43 \times 43 \times 4 . \\
\mu \mathrm{m}^{3} \\
\end{array}$ & Yes & Yex & 20 & No & $\begin{array}{c}\text { Sharief et al } \\
2000 \mathrm{~s}\end{array}$ \\
\hline$L x$ vivo & $(5 / 14 L / 6)$ & Male & $\infty-18$ & 14 & 9.4 Iesla & $\begin{array}{l}\mathrm{T}_{1} \\
\mathrm{~T}_{2} \\
\mathrm{~T}_{2^{*}}\end{array}$ & $\underset{1 \mathrm{~m} 2}{21.5 \times 21.5 \times 21.5}$ & Yes & Yes & 31 & No & $\begin{array}{c}\text { Jchnyon et al, } \\
2010\end{array}$ \\
\hline$\Gamma x$ vive & $C 5 \pi 3 \mathrm{~T} / 6 \mathrm{~J}$ & Male & 84 & 18 & 16.4 Tesila & $\mathrm{T} 1 / \mathrm{T}^{2} \mathrm{~B}$ & $\begin{array}{c}30 \times 30 \times 30 \\
\mu \mathrm{m}^{2}\end{array}$ & Ye: & $\begin{array}{c}\text { Yes } \\
\text { (Partial. } \\
\text { hipnosampus) }\end{array}$ & 40 & No & $\begin{array}{l}\text { Richards el al. } \\
2011\end{array}$ \\
\hline Kx vivo & (57/. J & Male & 84 & 18 & $16.4 \mathrm{Tss} / \mathrm{s}$ & $17 / 12^{\circ}$ & $\underset{30 \times 30 \times 30}{\mu^{3}}$ & Yes & $\begin{array}{c}\text { Yes } \\
\text { (I'artial: } \\
\text { cerebellum) }\end{array}$ & 38 & No & $\begin{array}{l}\text { Ulmometal, } \\
\qquad 20 / 3\end{array}$ \\
\hline lix พxพy & (ร) & Male & $\mathrm{x} 1$ & Is & 164 Testa & $11 / 1)^{*}$ & $\begin{array}{c}30 \times 30 \times 30 \\
\mu \mathrm{m}^{3}\end{array}$ & $V_{e s}$ & $\begin{array}{c}\text { Yes } \\
\text { (Piarlial' hocal } \\
\text { yarryllia) }\end{array}$ & अ & No & $\begin{array}{l}\text { IJlman at al, } \\
\quad 2013\end{array}$ \\
\hline Kx vivo & (57bi//G) & Male & 84 & 18 & 16.4 Tes/a & $\mathrm{T} 1 / \mathrm{I} 2^{\circ}$ & $\begin{array}{c}30 \times 30 \times 30 \\
\mu^{3}\end{array}$ & Yes & $\begin{array}{c}\text { Ycs } \\
\text { (l'artial: } \\
\text { neocurlex) }\end{array}$ & 74 & No & $\begin{array}{l}\text { Ullman et at, } \\
\text { zo/3 }\end{array}$ \\
\hline In vivo & 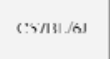 & Male & $1 \% n$ & $x$. & $4 /$ Tesla & $\mathrm{T}_{2}$ & $\underset{\mu m 1^{9}}{7 n \times 70 \times 70}$ & No & $\mathrm{NA}$ & $\mathrm{NA}$ & Yes & $\begin{array}{l}\text { Surwual et al, } \\
2013\end{array}$ \\
\hline Kx vivo & (57) & Male & 81 & 18 & 16.4 Teslas & $17 / 12^{\circ}$ & $\begin{array}{c}30 \times 30 \times 30 \\
\mu \mathrm{m}^{3}\end{array}$ & Yes & $\begin{array}{c}\text { Yex } \\
\text { (l'artial: } \\
\text { diutecphalon) }\end{array}$ & 89 & No & $\begin{array}{l}\text { Watson et ol, } \\
2017\end{array}$ \\
\hline Tx yevo & $C 5 \pi 3 \pi / 6 \mathrm{~J}$ & $\begin{array}{l}1.051 \text { males } \\
62.1 \text { fomale }\end{array}$ & 77 & 1675 & NA & NA & $\underset{\mu \mathrm{m}^{2}}{10 \times 10}$ & No & Ycs & 1327 & No & $\begin{array}{c}\text { Wang et al } \\
2 m \geq 0\end{array}$ \\
\hline
\end{tabular}

658 Table 1. Comparison of mouse brain resources currently available in the literature $(\mathrm{NA}=$ not

659 available). 


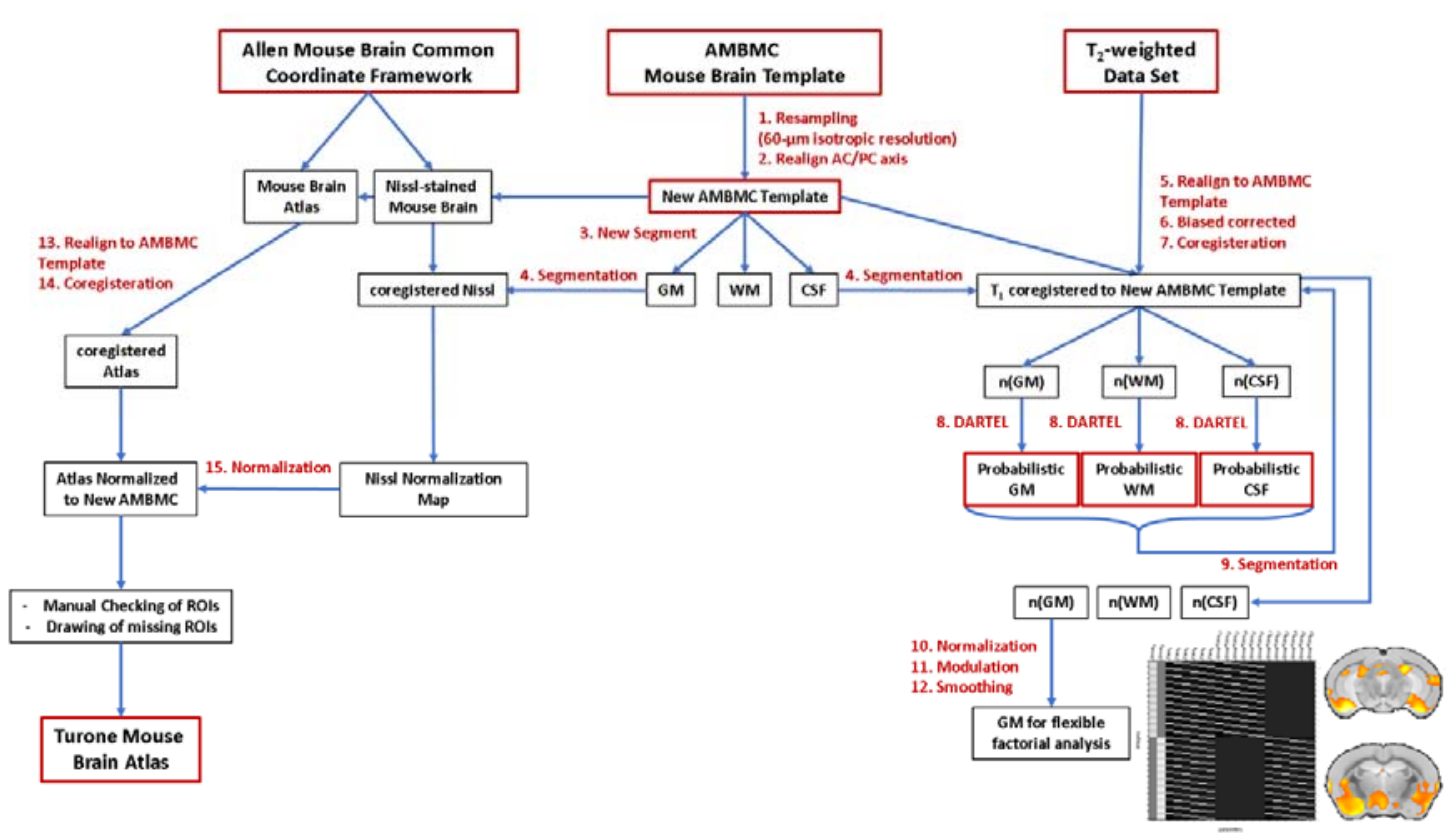

661

662

663

664

665

666

667

668

669

670

671

672

673

674

675

Figure 1. Processing of mouse brain templates and building an atlas from the AMBMC template and Allen Brain Atlas for data analysis and visualization. To create our resources, we used both AMBMC mouse brain template and the mouse Allen Brain Atlas and its associated Nissl images. (1) We down-sampled to a suitable resolution for MRI analysis (60$\mu \mathrm{m}$ isotropic resolution) and (2) realign in the $\mathrm{AC} / \mathrm{PC}$ axis. The resulting template was then segmented into GM, WM and CSF probability maps (3). These probability maps were used to segment all the images which have been previously normalized to the template $(\mathbf{5 , 6 , 7})$. We obtained a large set of 138 images for each tissue class which have been used to build a population-specific GM, WM and CSF priors. using an exponentiated lie algebra (DARTEL) approach (8). This new set of population-specific tissue priors was used to segment again normalized $\mathrm{T}_{2}$ images $(\mathbf{9})$ for the final $\operatorname{VBM}$ preprocessing $(\mathbf{1 0}, \mathbf{1 1}, \mathbf{1 2})$. To normalize the Allen Brain Atlas, we manually realign (13) and normalized the associated Nissl-stain mouse brain using the GM priors generated previously $(\mathbf{1 4}, \mathbf{1 5})$. Both linear and nonlinear transformations have been applied to the Allen mouse brain atlas. Then, a visual inspection of 
676 each normalized label was carried out and, when necessary, redrawn according to Paxinos and

677 Franklin's atlas. Finally, the olfactory bulb and hind brain regions were completed, the corpus

678 callosum and ventricles were drawn from the WM and CSF priors, and the cerebellum labels

679 were replaced by the AMBMC cerebellum labels.

$680 \mathrm{AMBMC}=$ Australian Mouse Brain Mapping Consortium mouse brain template, $\mathrm{AC} / \mathrm{PC}=$

681 anterior commissure/posterior commissure, $\mathrm{CSF}=$ cerebrospinal fluid, $\mathrm{GM}=$ gray matter,

$682 \mathrm{WM}=$ white matter. 
A

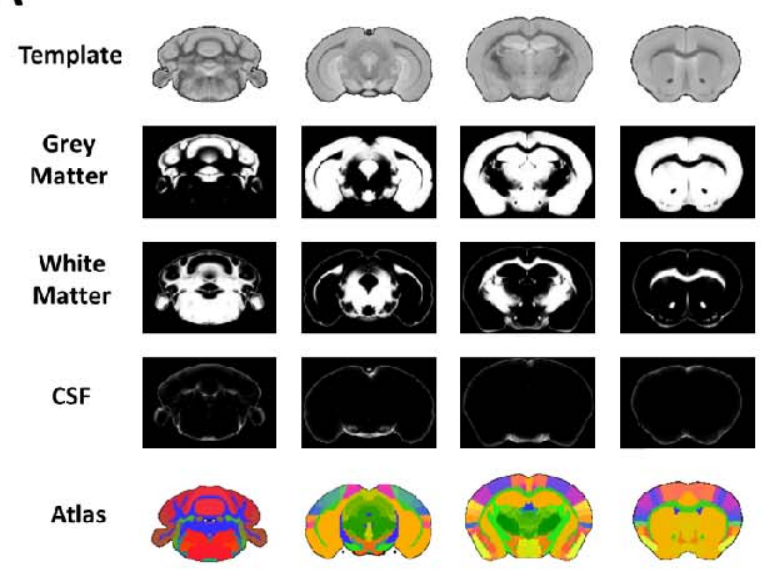

B

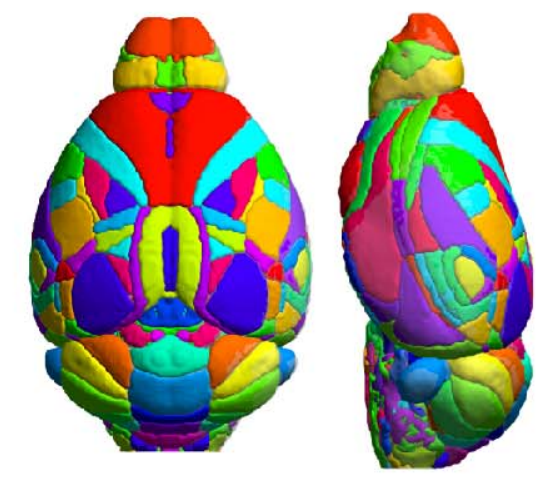

D
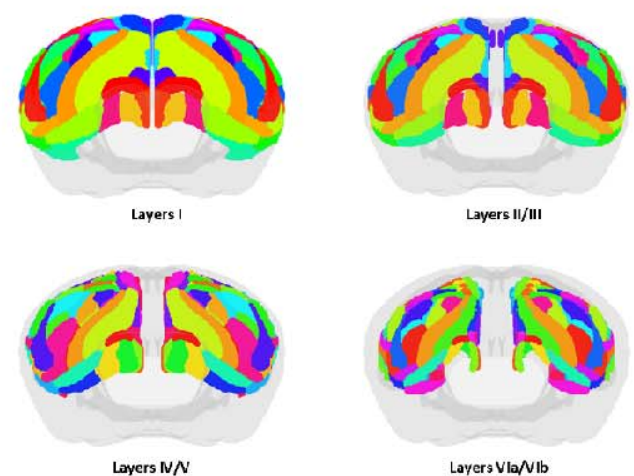

$\mathbf{F}$
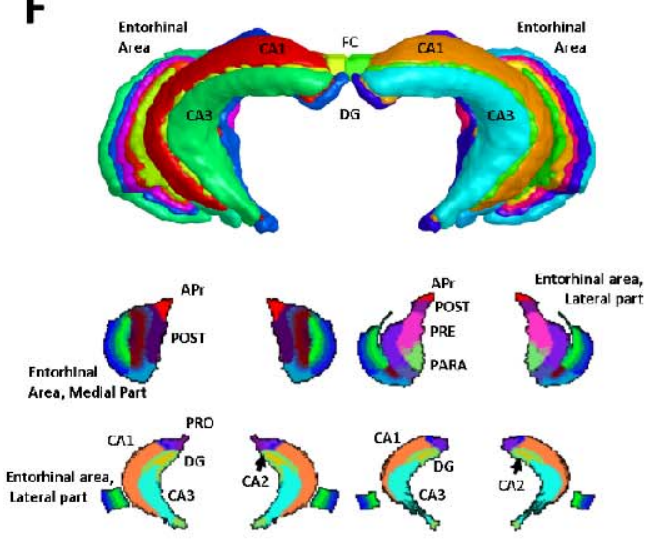

$\sum_{C A 3}^{C A 1} D^{[A 2}$
E

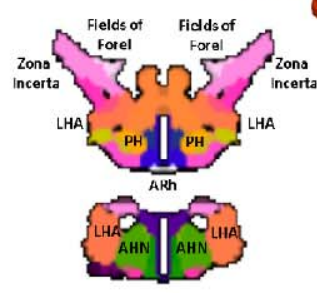

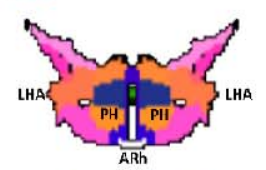

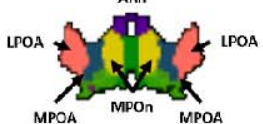

C

684 Figure 2. Details of the mouse brain template and atlas. (A) Coronal slices of the anatomical 685 template of the mouse brain and the corresponding gray matter, white matter and 
686 cerebrospinal fluid probabilistic maps and the associated anatomical atlas $(60-\mu \mathrm{m}$ isotropic 687 resolution). (B) Dorsal (left panel) and lateral (right panel) 3D representations of the 688 anatomical mouse brain atlas. (C) Lateral views of the cortical areas after normalization of the 689 Allen Mouse Brain Atlas to the AMBMC anatomical template. The cortex was segmented 690 into cortical areas such as the cingulate, visual, auditory, frontal, visceral, insular, olfactory, 691 retrosplenial, motor, somatosensory, temporal, entorhinal and gustatory systems. Each area 692 was subdivided into secondary areas (e.g., primary and secondary motor cortices) or structural 693 areas (i.e., agranular, dysgranular, agranular/dysgranular, granular and posterior agranular insular cortices). (D) The four images depict the different cortical layers (I, II/III, IV/V and $\mathrm{VIa} / \mathrm{VIb}$ ). (E and $\mathbf{F})$ 3D rendering and axial sections of subcortical structures (hypothalamus 696 and hippocampus).

697 Legend for labeled regions: Hypothalamus: ARh = arcuate hypothalamic nucleus; LHA = 698 lateral hypothalamic area; $L P O A=$ lateral preoptic area $; M P O A=$ medial preoptic area; 699 MPOn = medial preoptic nucleus; $P H=$ posterior hypothalamic nucleus. $A H N=$ anterior 700 hypothalamic nucleus.

701 Hippocampus: $A p r=$ area prostriata; CA1, CA2, CA3 = cornu ammonis areas 1, 2 and 3; $D G=$ dentate gyrus; $F C=$ fasciola cinerea $;$ PARA = parasubiculum; POST $=$ postsubiculum; $P R O=$ prosubiculum $;$ PRE = presubiculum. For further details, see

704 https://www.nitrc.org/projects/tmbta_2019. 

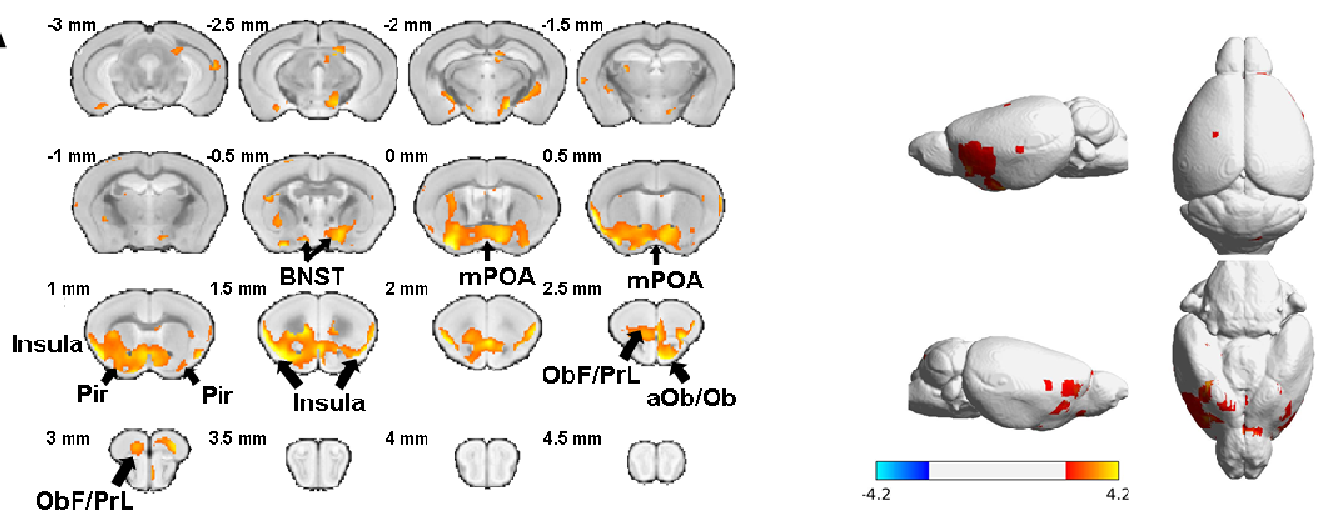

B
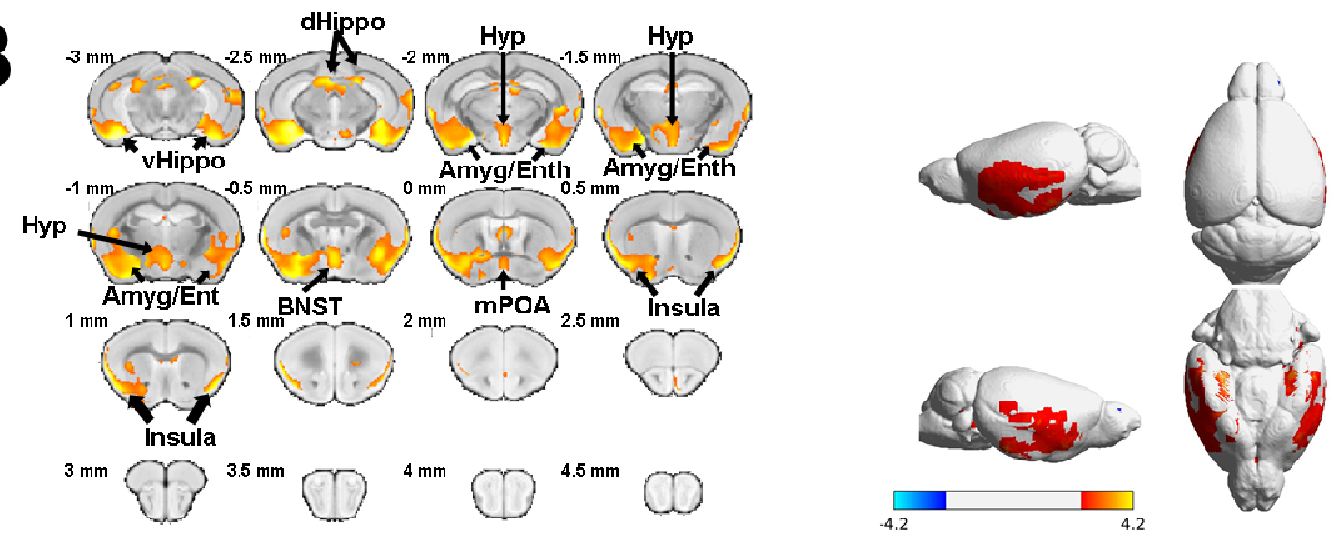

C
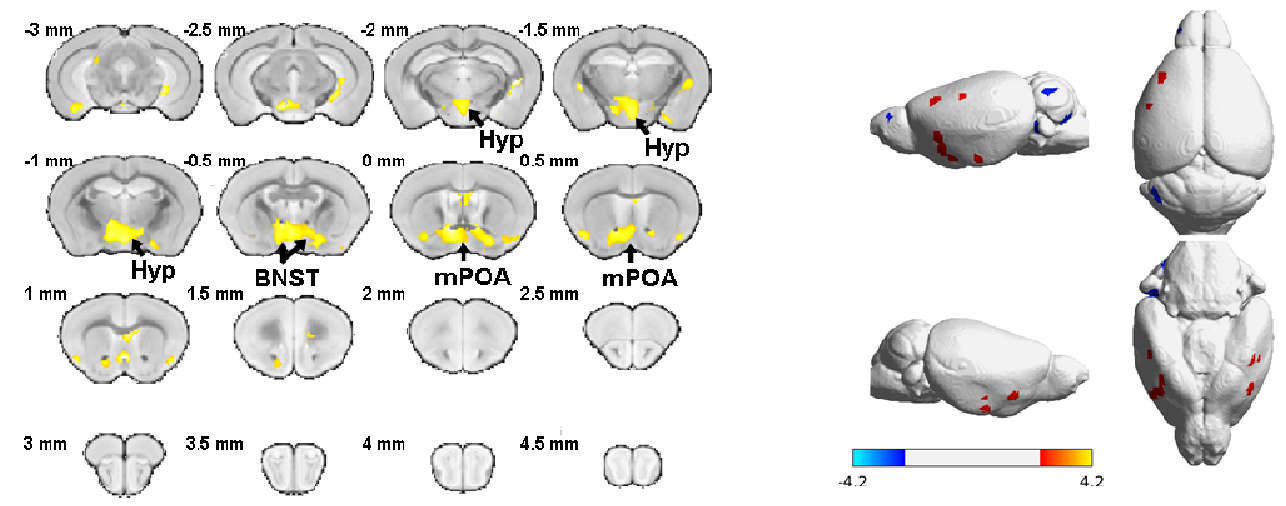

706 Figure 3. Longitudinal effects of the reproductive cycle on brain morphometry. Coronal

707 slices (at left) and brain plots (at right) showing gray matter concentration (GMC) differences

708 between control and parous animals at the end of gestation (A) and during early lactation (B)

709 and late lactation $(\mathbf{C})$.

710 SPM flexible factorial analysis revealed an interaction between control mice and parous mice in the late gestation period (A), early lactation period (B) and late lactation period (C); voxel- 
bioRxiv preprint doi: https://doi.org/10.1101/2020.05.23.112045; this version posted June 19, 2020. The copyright holder for this preprint

(which was not certified by peer review) is the author/funder, who has granted bioRxiv a license to display the preprint in perpetuity. It is made available under aCC-BY-ND 4.0 International license.

712 level threshold $p<0.01, \mathrm{t}_{(126)}=2.356$, cluster threshold $=25$ voxels. $B N S T=$ bed nucleus of

713 the stria terminalis; Hyp = hypothalamus; $m P O A=$ medial preoptic area $;$ dHippo $=$ dorsal

714 hippocampus; $\mathrm{ObF} / \mathrm{PrL}=$ orbitofrontal/prelimbic area $;$ aOb/Ob $=$ accessory olfactory

715 nucleus/olfactory bulb; Pir = piriform cortex; Amyg/Ent = amygdala/entorhinal cortex. 

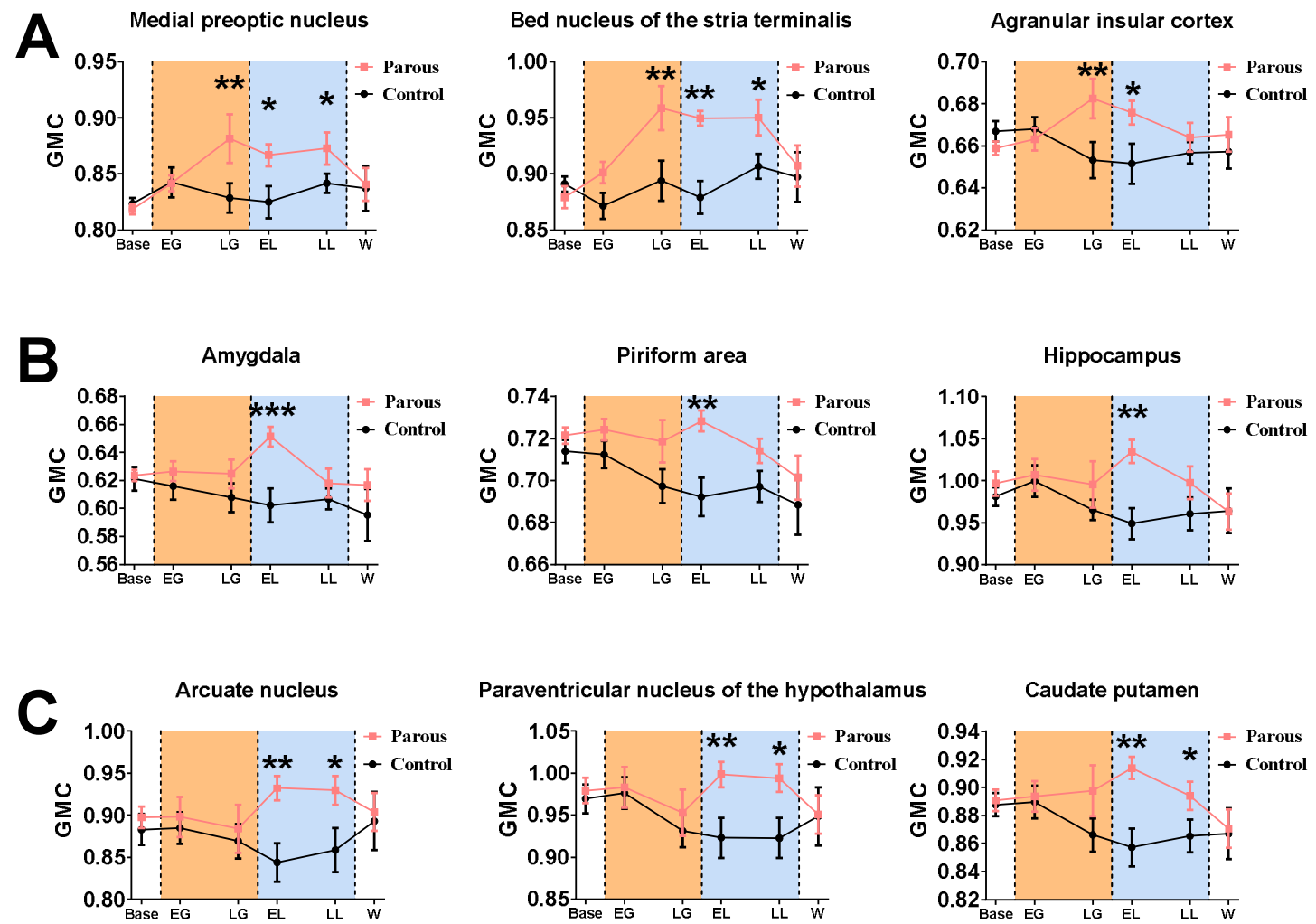

716

717 Figure 4. Longitudinal time course analysis of gray matter concentration (GMC) over the reproductive cycle. Time course comparisons in GMC between the control (black dots and lines) and parous (red dots and lines) groups showing 3 different time profiles. (A) GMC values within the medial preoptic area, the bed nucleus of stria terminalis (BNST) and the agranular insular cortex reveal a significant increase in GMC during the late gestation (LG) period maintained until weaning (W). (B) Specific and transient increases in GMCs are observed in the amygdala, the piriform area and the hippocampus during early lactation (EL). (C) The arcuate nucleus, PVN and caudate putamen display an increase in GMC through both EL and late lactation (LL) periods.

726 Orange and blue areas represent the gestation and lactation periods, respectively. Data are expressed as the mean \pm standard error of the mean (SEM); two-way ANOVA followed by Holm-Sidak multiple comparisons test; $* p<0.05, * * p<0.01$ and $* * * p<0.001$, compared with control mice. 


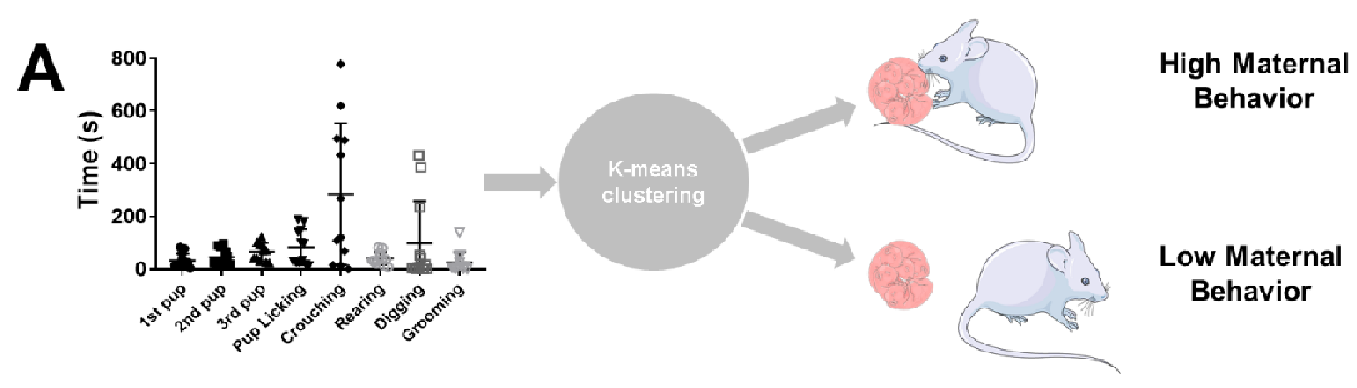

B

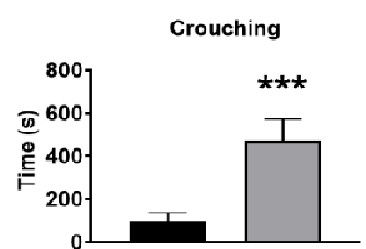

C

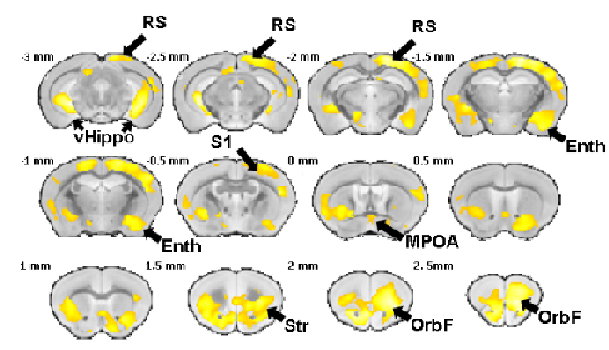

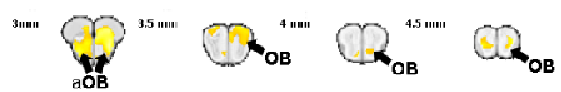

D
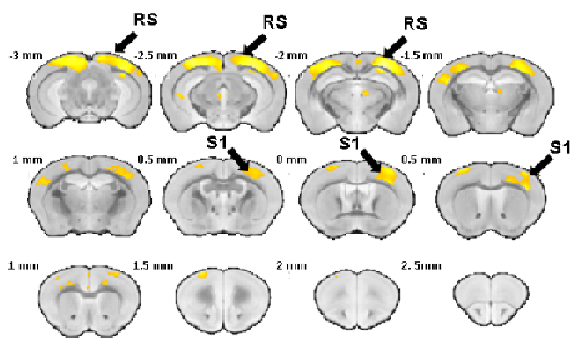

${ }^{3 m n} D^{3.5 m m} D^{4 m n} D^{4.5 m m} C$

Pup Licking
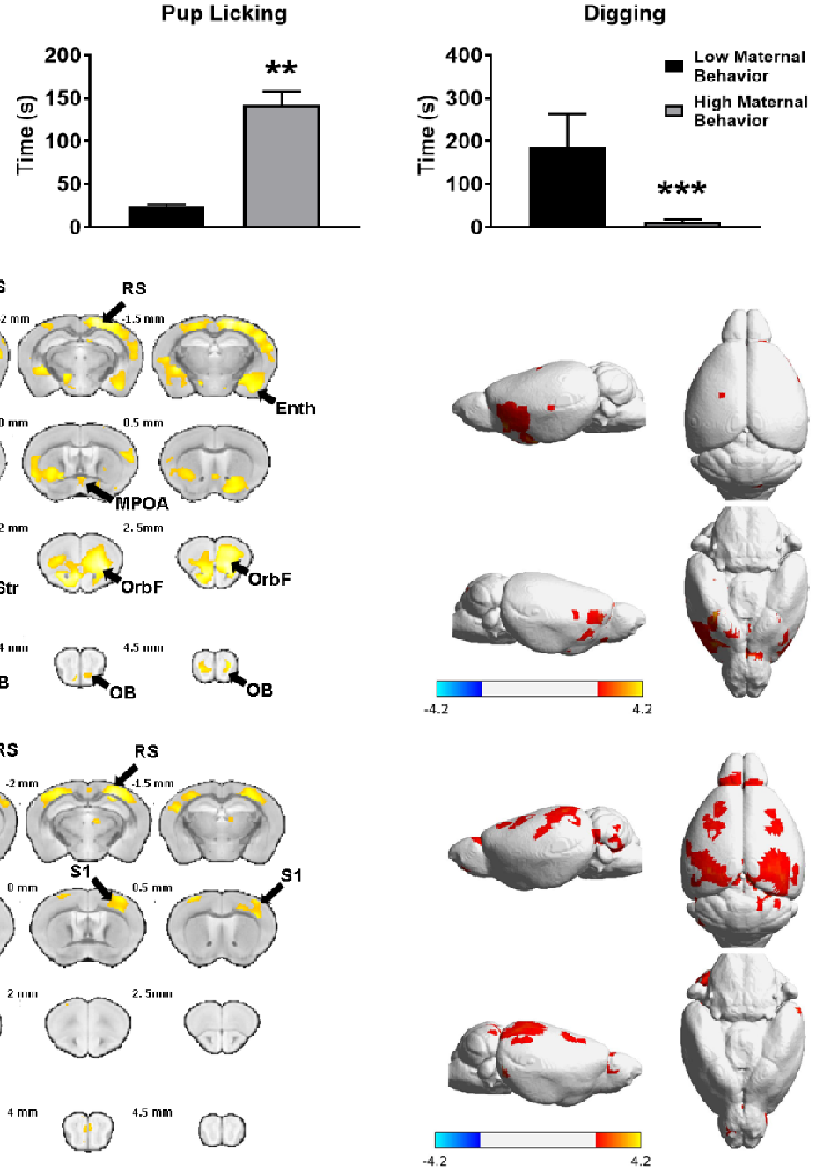

731 Figure 5. Distribution of animals according to the quality of their maternal behavior assessed

732 with the pup retrieval test and brain morphometric. K-means clustering of parous animals to

733 classify mice into low and high maternal behavior groups based on behavior during the pup

734 retrieval test (A). Comparisons between the low and high maternal behavior groups revealed

735 significant differences in crouching, pup-licking and digging times (B). Brain slices (left

736 panel) and brain plots (right panel) comparing gray matter concentration (GMC)

737 modifications and surface maps of GMC differences between females exhibiting low and 
738 those exhibiting high maternal behavior at the end of the gestation period (C) and early

739 lactation period (D).

740 Low and high maternal behavioral data were compared using a Student's t-test with post hoc

741 corrections for multiple comparisons using an FDR approach $(\mathrm{Q}=1 \%)$ and are expressed as

742 the mean \pm SEM; $* * p<0.01$ and $* * * p<0.001$. SPM flexible factorial analysis revealed an

743 interaction between low and high maternal behavior parous mice in the late gestation period

744 (A) and early lactation period (B); voxel-level threshold $p<0.01, \mathrm{t}_{(60)}=2.39$, cluster

745 threshold $=25$ voxels. $R S=$ retrosplenial cortex; vHippo $=$ ventral hippocampus; $S 1=$

746 primary somatosensory cortex; $a O B=$ accessory olfactory bulb; $O B=$ olfactory bulb; Pir $=$

747 piriform cortex $;$ Enth = entorhinal cortex $;$ Str $=$ striatum $;$ OrbF $=$ orbitofrontal cortex. 

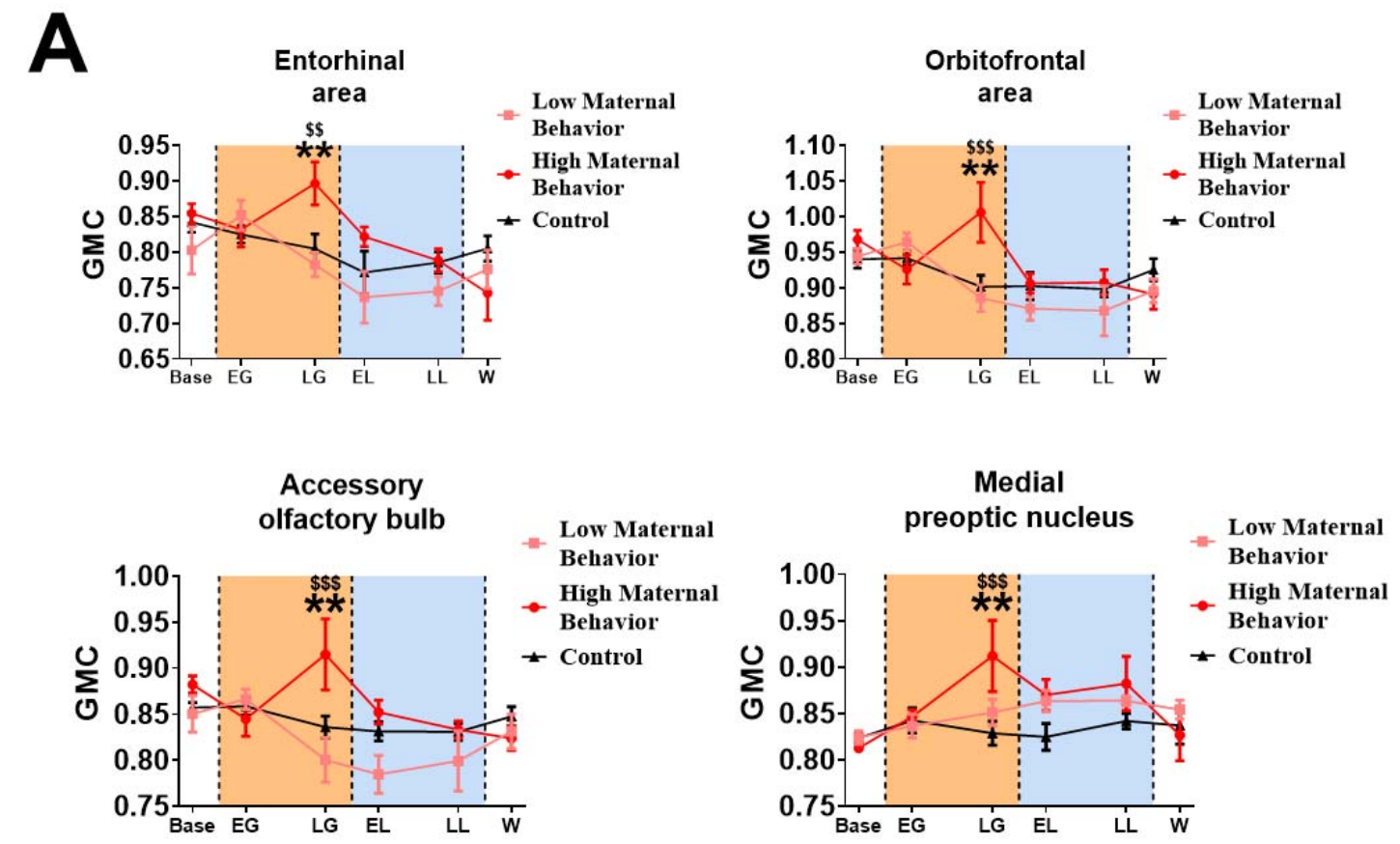

B
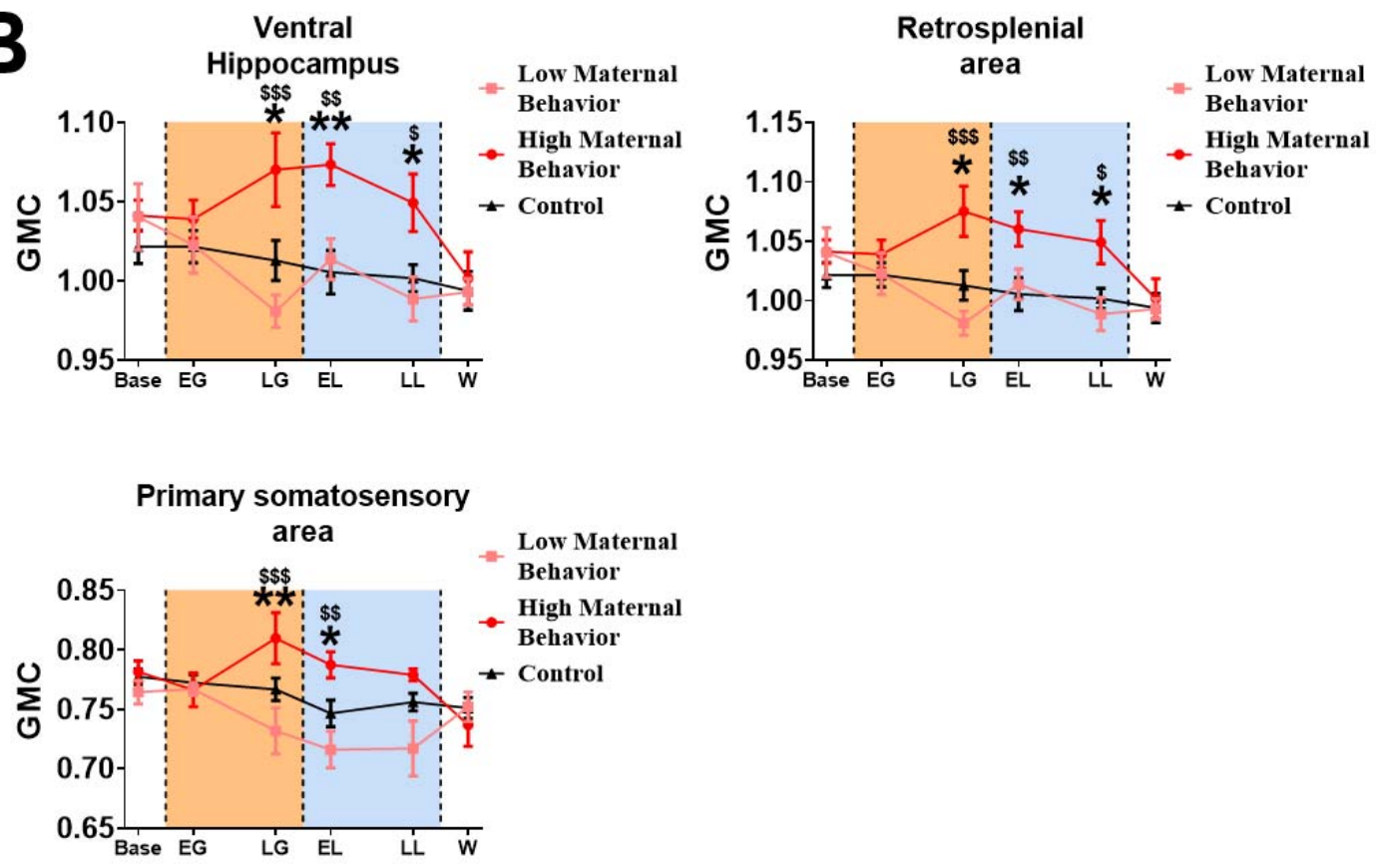

749 Figure 6. Longitudinal analysis in gray matter concentration (GMC) during the reproductive cycle in control females and females exhibiting low or high maternal behavior. Time-course comparison of GMC between the control (black dots and lines), low maternal behavior (pink dots and lines) and high maternal behavior (red dots and lines) groups revealed two types of 
753 time profile. GMC analysis in the entorhinal area, orbitofrontal area, the accessory olfactory

754 bulb and the medial preoptic nucleus revealed an acute and specific increase in GMC values

755 in the high maternal behavior group at the late gestation period (A). In contrast, GMC analysis

756 in the ventral hippocampus, the retrosplenial area and the primary somatosensory area

757 revealed an increase in GMC in the high maternal behavior group at the late gestation period,

758 and this increase was maintained until weaning $(\mathbf{B})$.

759 Orange and blue areas represent the gestation and lactation periods, respectively. Data were

760 compared using a two-way ANOVA followed by Holm-Sidak multiple comparisons test and

761 expressed as the mean $\pm \mathrm{SEM} ; * p<0.05, * * p<0.01$ when high maternal mice were

762 compared with control mice and $\$ \$ p<0.01, \$ \$ p<0.001$ when high maternal mice were

763 compared with low maternal mice. 


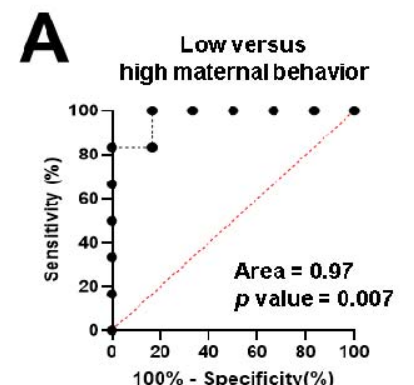

B
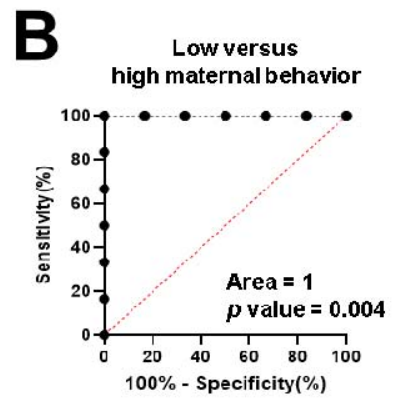
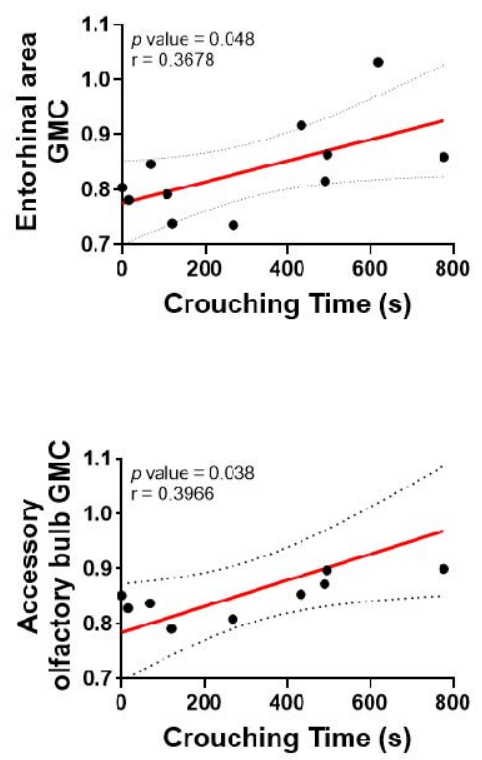
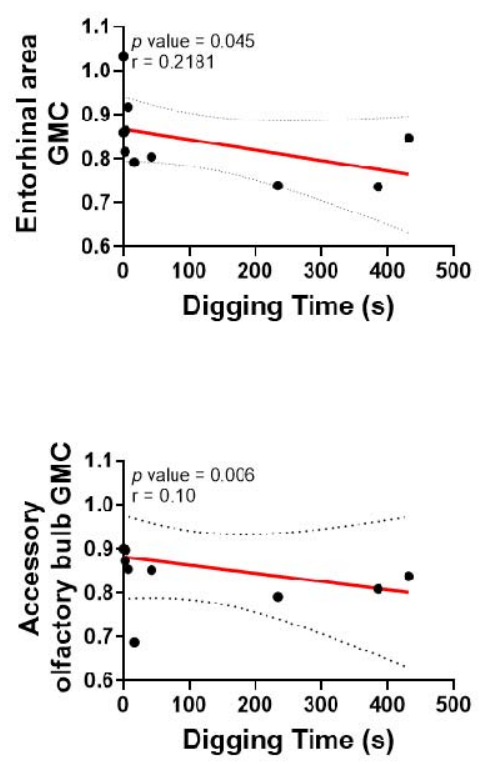

764

765 Figure 7. Estimation of the sensitivity and specificity of late-gestation GMC measures in the

766 entorhinal area (A) and accessory olfactory bulb (B) to predict postpartum maternal

767 performance.

768 Receiver operating characteristic (ROC) curves were estimated using a Wilson/Brown test

769 with a $95 \%$ confidence interval. Correlations were estimated using a Pearson correlation test.

770 ROC and correlation analyses were considered significant at $p<0.05$. 
bioRxiv preprint doi: https://doi.org/10.1101/2020.05.23.112045; this version posted June 19, 2020. The copyright holder for this preprint (which was not certified by peer review) is the author/funder, who has granted bioRxiv a license to display the preprint in perpetuity. It is made available under aCC-BY-ND 4.0 International license.

\section{Supplementary Data}

\begin{tabular}{|c|c|c|c|c|c|c|c|}
\hline \# I abel & Region of Interest & ITemisphere & T Value & $p$ Value & $\mathbf{x}\{\mathrm{mm}\}$ & $\mathbf{y}\{\mathrm{mm}\}$ & $x\{m m\}$ \\
\hline 712 & Visceral arca, layer $2 / 3$ & Left & 2.3789 & 0.0094 & -41.5 & -3.5 & -3.5 \\
\hline 1842 & Agranular msular arcia, dorsial part, layer $2 / 3$ & I.elt & 3.9264 & 60.0001 & -34.5 & 16.5 & -8.5 \\
\hline 652 & Gustutuly atcen, Inye $2 / 3$ & Left & 3.4262 & 0.0004 & -30.5 & 25.5 & -4.5 \\
\hline 2562 & Cortical amygdalar aren, posterinr part, medial $7 n n e$ & T eft & 2.6591 & 00044 & -2.35 & -165 & -185 \\
\hline $3(0) 2$ & ()lfactory tubcrele & I.cft & 4.2298 & $<0.0001$ & -22.6 & 1.3.5 & -2.3 .5 \\
\hline 2502 & P'ififum aแผ & Luft & 3.6483 & 0.0002 & -21.5 & 26.5 & -14.5 \\
\hline $312 \%$ & Medial amygdalar mucleus & T eft & $2.505 \%$ & 00067 & -9.15 & -105 & $-11 ;$ \\
\hline 2972 & Caudoputamen & I.cft & 2.5003 & 0.0068 & -20.5 & 7.5 & -6.5 \\
\hline 3522 & T.atcral dorsal nucleus of thalamus & T.ch & 2.3933 & 0.0090 & -17.5 & -4.5 & 4.5 \\
\hline 292 & l'nmary somatosensory area, lower lmb, hayer 2/3 & Lalt & 2.1131 & 0.0086 & 16.5 & 1.5 & 23.5 \\
\hline 1602 & Orbital areu, laleral parl, layer $2 / 3$ & Left & 2.4677 & 0.0074 & -15.5 & 37.5 & -0.5 \\
\hline 2462 & Anterior olfectury nucleus & Lefl & 2.3608 & 0.0098 & -11.5 & 33.5 & -5.5 \\
\hline 4132 & T.ateral hypothalamic area & T efft & 2.52 .17 & 00064 & -105 & -105 & -185 \\
\hline 2982 & Nucleus accumbens & T.cht & 2.3953 & 0.0090 & -9.5 & 18.5 & -15.5 \\
\hline 3192 & Diagonal band nuclcus & Left & 2.5835 & 0.0054 & -5.5 & 14.5 & -22.5 \\
\hline 1731 & ()rbital area, medial part, layer 1 & Right & 2.5912 & 0.0053 & 1.5 & 37.5 & 0.5 \\
\hline 2421 & Main ulfactury bulb & Kight & 3.7602 & 0.0001 & 2.5 & 35.5 & -17.5 \\
\hline 3861 & Medial prenptic area & Right. & 2.6983 & 00040 & 65 & 115 & -2.15 \\
\hline $39 / 1$ & Anterior hypothalamic nucleus & Right & $2.41 \% 3$ & 0.0uxs & 8.5 & $-(1.6)$ & -20.5 \\
\hline 4201 & Tuberal mucleus & Right & 2.4250 & 0.0083 & 8.5 & -3.5 & -20.5 \\
\hline 4131 & I.aleral hypothalame area & Kight & 3.3026 & 0.0006 & 11.5 & -10.5 & -16.5 \\
\hline 11 & Frontal polc, layer 1 & Right & 2.5614 & 0.0058 & 12.5 & 41.5 & 5.5 \\
\hline 4141 & Laleral preuptic area & Right & 2.5685 & 0.0057 & 12.5 & 5.5 & -18.5 \\
\hline 2161 & Antenor ollactory nuckeus & Kught & 2.1111 & 0.0086 & 11.5 & 35.5 & 7.5 \\
\hline 2631 & Dentale gyrus, molecular layer & Kight & 2.4871 & 0.0071 & 14.5 & -16.5 & 12.5 \\
\hline 3121 & Medial amygdalau nucleus & Right & 2.6129 & 0.0050 & 21.5 & -10.5 & -11.5 \\
\hline 3001 & Olfastory tuhercle & Right. & 2.3745 & 00095 & 22.5 & 105 & -245 \\
\hline 1841 & Agranular insular arcia, dorsal part, layer $2 / 3$ & Right & 3.0066 & 0.0016 & 23.5 & 32.5 & -2.5 \\
\hline 2501 & Piriform arca & Right & 2.9740 & 0.0018 & 26.5 & 24.5 & -12.5 \\
\hline 2971 & Caudoputamen & Right & 2.7880 & 0.0031 & 27.5 & -7.5 & -5.5 \\
\hline 621 & Supplomentel somatusensory ared, leyer $6 \mathrm{a}$ & Kightit & 2.4045 & 0.0088 & 29.5 & 8.5 & 2.5 \\
\hline 591 & Supplemental somatosensory area, layer $9 / 3$ & Right. & 2.5647. & 00057 & 365 & 165 & -05 \\
\hline
\end{tabular}

773 Table S1. Local variation in gray matter concentration between control and parous mice at the

774 end of the gestation period. SPM flexible factorial analysis revealed an interaction between

775 the control and parous groups at the late gestation time point. 
bioRxiv preprint doi: https://doi.org/10.1101/2020.05.23.112045; this version posted June 19,2020. The copyright holder for this preprint (which was not certified by peer review) is the author/funder, who has granted bioRxiv a license to display the preprint in perpetuity. It is made available under aCC-BY-ND 4.0 International license.

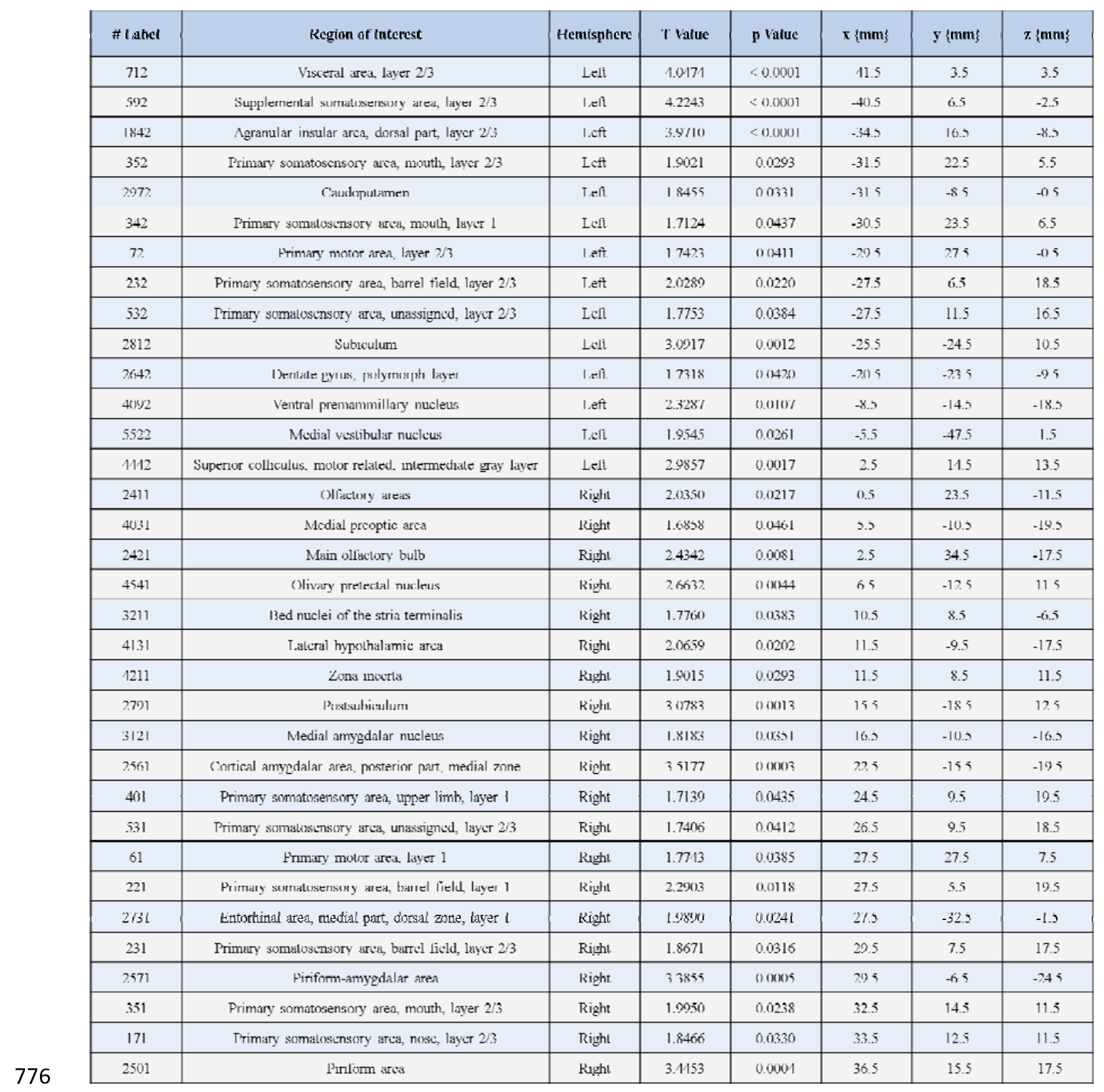

777 Table S2. Local variation in gray matter concentration between control and parous mice at the

778 beginning of the lactation period. SPM flexible factorial analysis revealed an interaction

779 between the control and parous groups at the early lactation time point. 
bioRxiv preprint doi: https://doi.org/10.1101/2020.05.23.112045; this version posted June 19, 2020. The copyright holder for this preprint (which was not certified by peer review) is the author/funder, who has granted bioRxiv a license to display the preprint in perpetuity. It is made available under aCC-BY-ND 4.0 International license.

\begin{tabular}{|c|c|c|c|c|c|c|c|}
\hline \# I abel & IRegion of Interest & Ilemisphere & T Value & $p$ Value & $\mathrm{x}\{\mathrm{mm}\}$ & $\mathbf{y}\{\mathbf{m m}\}$ & $\mathrm{x}\{\mathrm{mm}\}$ \\
\hline 712 & Viscoral arca, layer $2 / 3$ & Lill & 2.1741 & 0.01566 & 11.5 & 0.5 & 2.5 \\
\hline 2812 & Subiculum & Leli & 2.0845 & 0.01938 & -28.5 & -24.5 & 9.5 \\
\hline 2972 & Caudizulamerı & I.eft & 2.87 .35 & 0.00238 & -28.5 & -7.5 & -3.5 \\
\hline 25002 & I'iriform arca & I.cft & $2.301 \%$ & 0.01143 & -21.5 & 16.5 & -16.5 \\
\hline 2562 & Cortical anygdalar arca, posterior part, medial zonc & Left & 2.2071 & 0.01445 & -23.5 & -17.5 & -17.5 \\
\hline 2992 & Fundus of strialum & Left & 2.0065 & 0.0232 & .20 .5 & 8.5 & -17.5 \\
\hline 4442 & Superior colliculus, motor related, intenmediate gray layer & l.eft & 1.9022 & 002927 & -16.5 & -21.5 & 105 \\
\hline 2142 & Anterior visual area, layer $2 / 3$ & T.eft & 1.7105 & 0.04382 & -1.3 .5 & -0.5 & 25.5 \\
\hline 4082 & Dorsal premammillary nucleus & T.ell & 2.6229 & 0.00488 & -5.5 & -14.5 & -1.5 .5 \\
\hline 3011 & Latcral scptal nucleus, caudal (caudodorsal) part & Right & 2.2155 & 0.01416 & 1.5 & 8.5 & 7.5 \\
\hline 3861 & Medial propplic arca & Right & 2.8305 & 0.0027 & 6.5 & 11.5 & -21.5 \\
\hline 3211 & Bet nucket of the stria teminalis & Right & 1.7190 & 0.01052 & 7.5 & 14.5 & 12.5 \\
\hline 4131 & Laleral hypothalame area & Kight & 1.7001 & 0.03721 & 11.5 & -6.5 & -17.5 \\
\hline 262.1 & |نiels] C:A3 & Right. & 26408 & 0002465 & 2.15 & -185 & -655 \\
\hline 5161 & IJorsal cochlear nucleus & Right & $1.74 \pi$ & 0.04063 & 2.3.5 & -43.5 & -4.5 \\
\hline 2561 & Cortical anygdalar area, posterior part, medial zone & Right & 1.8753 & 0.03104 & 24.5 & -18.5 & -17.5 \\
\hline 2731 & Entorhinal arca, medial part. dorsal zonc, layer 1 & Right & 1.9285 & 0.02763 & 27.5 & -32.5 & -1.5 \\
\hline 2971 & Caudoputamen & Right & 2.8706 & 0.0021 & 30.5 & 8.5 & 1.5 \\
\hline 701 & Visceral area, layer 1 & Rightı & 1.8073 & 0.03589 & 41.5 & 3.5 & -3.5 \\
\hline
\end{tabular}

781 Table S3. Local variation in gray matter concentration between control and parous mice at the

782 end of the lactation period. SPM flexible factorial analysis revealed an interaction between the

783 control and parous groups at the late lactation time point. 
bioRxiv preprint doi: https://doi.org/10.1101/2020.05.23.112045; this version posted June 19,2020 . The copyright holder for this preprint (which was not certified by peer review) is the author/funder, who has granted bioRxiv a license to display the preprint in perpetuity. It is made available under aCC-BY-ND 4.0 International license.

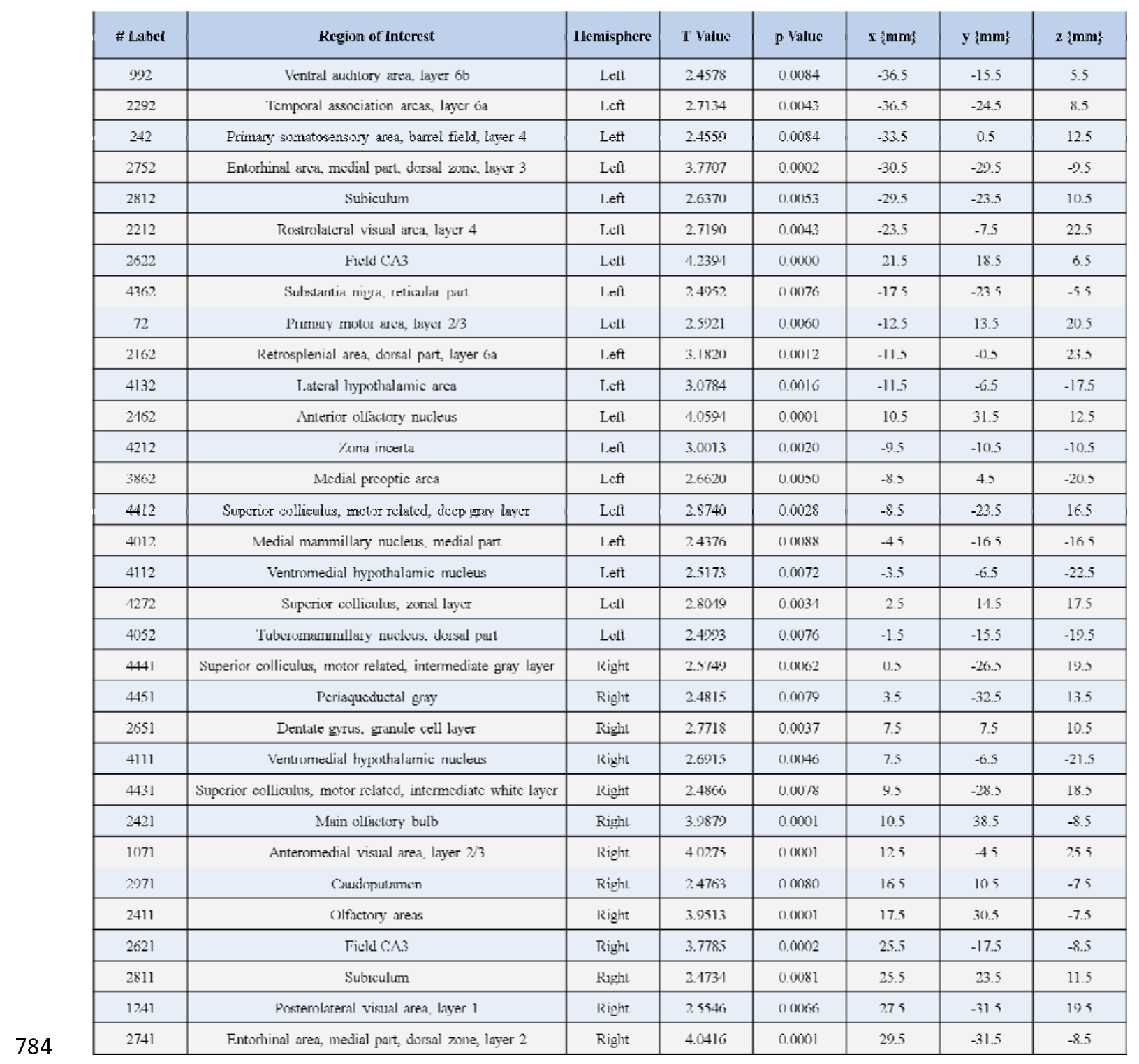

785 Table S4. Local variation in gray matter concentration between low maternal behavior parous

786 mice and high maternal behavior parous mice at the end of the gestation period. SPM flexible

787 factorial analysis revealed an interaction between the low versus high maternal behavior

788 groups at the late gestation time point. 
bioRxiv preprint doi: https://doi.org/10.1101/2020.05.23.112045; this version posted June 19, 2020. The copyright holder for this preprint (which was not certified by peer review) is the author/funder, who has granted bioRxiv a license to display the preprint in perpetuity. It is made available under aCC-BY-ND 4.0 International license.

\begin{tabular}{|c|c|c|c|c|c|c|c|}
\hline \# latel & Region of interest & Hemisphere & T Value & p Value & $x\{m m\}$ & $y\{m m\}$ & $\mathrm{z}\{\mathrm{mm}\}$ \\
\hline 2732 & Entorhinal arsa, modial part, dorsal zonv, layer 1 & Lell & 2.5882 & 0.0060 & 28.5 & 33.5 & 1.5 \\
\hline 2632 & Dentale gyrus, molecular layer & Leli & 2.5173 & 0.0072 & -20.5 & -16.5 & 6.5 \\
\hline 412 & P'rimary somatosensory area, upper limb, layer $2 / 3$ & I.eft & 3.1161 & 0.0014 & -19.5 & 14.5 & 18.5 \\
\hline 26002 & licld CMI & $L \mathrm{cft}$ & 2.5216 & $0.00 \% 0$ & -19.5 & -11.5 & $1 \%$ \\
\hline 122 & Sccondary motor arca, layer $2 / 3$ & Left & 2.8890 & 0.0027 & -15.5 & 24.5 & 15.5 \\
\hline 2422 & Main olfactory bulb & Lent & 3.5084 & 0.0004 & -8.5 & 45.5 & 6.5 \\
\hline 3657 & Parafascicular mucleus & I. eft: & 30525 & 00017 & -35 & -12.5 & -15 \\
\hline 2672 & Tnduseum griseum & T.eft & 2.4662 & 0.0082 & -1.5 & 19.5 & 5.5 \\
\hline 1482 & Anlcrior cingulate arca, dorsal part, layer I & T.cfl & 2.4675 & 0.0082 & -0.5 & 21.5 & 14.5 \\
\hline 2082 & Retrosplenial area, ventral part, layer 1 & T.eft & 2.391 .3 & 0.0099 & -0.5 & -3.5 & 2.3 .5 \\
\hline 2421 & Main ollactory bulb & Right & 2.7201 & 0.0043 & 2.5 & 43.5 & -14.5 \\
\hline 3651 & P'araliscicular nuclcus & Right & 2.9370 & 0.0023 & 6.5 & 12.5 & 0.5 \\
\hline 2411 & Olfactory yutes & Kipht & 3.2067 & 0.0008 & 8.5 & 42.5 & 4.5 \\
\hline 26011 & liield ('A 1 & Right: & 36131 & 00003 & 185 & -95 & 175 \\
\hline 381 & Primary somatosensory area, mouth, layer ca & Kight & $3.14 .5 \mid$ & 0.0013 & 24.5 & 14.5 & 5.5 \\
\hline 2821 & Prissubiculum & Right & 2.985 .3 & 0.0020 & 24.5 & -19.5 & 14.5 \\
\hline 2691 & Entorhinal area, lateral part, layer 2 & Right & 3.0830 & 0.0015 & 38.5 & 29.5 & 5.5 \\
\hline
\end{tabular}

790 Table S5. Local variation in gray matter concentration between low maternal behavior parous

791 mice and high maternal behavior parous mice at the beginning of the lactation period. SPM

792 flexible factorial analysis revealed an interaction between the low versus high maternal

793 behavior groups at the early lactation time point. 